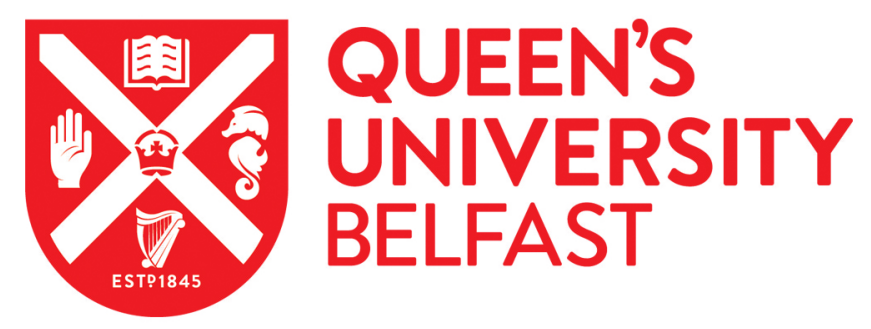

\title{
Reconstructing the accumulation history of a saltmarsh sediment core: Which age-depth model is best?
}

Wright, A. J., Edwards, R. J., van de Plassche, O., Blaauw, M., Parnell, A. C., van der Borg, K., de Jong, A. F. M., Roe, H. M., Selby, K., \& Black, S. (2017). Reconstructing the accumulation history of a saltmarsh sediment core: Which age-depth model is best? Quaternary Geochronology, 39, 35-67.

https://doi.org/10.1016/j.quageo.2017.02.004

Published in:

Quaternary Geochronology

Document Version:

Peer reviewed version

Queen's University Belfast - Research Portal:

Link to publication record in Queen's University Belfast Research Portal

\section{Publisher rights}

Copyright 2017 Elsevier

This manuscript version is published under a Creative Commons Attribution-NonCommercial-NoDerivs License

(https://creativecommons.org/licenses/by-nc-nd/4.0/), which permits distribution and reproduction for non-commercial purposes, provided the author and source are cited.

\section{General rights}

Copyright for the publications made accessible via the Queen's University Belfast Research Portal is retained by the author(s) and / or other copyright owners and it is a condition of accessing these publications that users recognise and abide by the legal requirements associated with these rights.

Take down policy

The Research Portal is Queen's institutional repository that provides access to Queen's research output. Every effort has been made to ensure that content in the Research Portal does not infringe any person's rights, or applicable UK laws. If you discover content in the Research Portal that you believe breaches copyright or violates any law, please contact openaccess@qub.ac.uk. 


\section{Accepted Manuscript}

Reconstructing the accumulation history of a saltmarsh sediment core: Which agedepth model is best?

Alexander J. Wright, Robin J. Edwards, Orson van de Plassche, Maarten Blaauw, Andrew C. Parnell, Klaas van der Borg, Arie F.M. de Jong, Helen M. Roe, Katherine

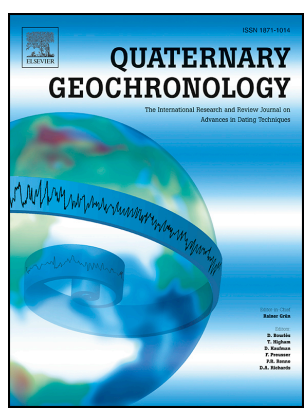
Selby, Stuart Black

PII:

S1871-1014(16)30090-5

DOI:

10.1016/j.quageo.2017.02.004

Reference: QUAGEO 825

To appear in: Quaternary Geochronology

Received Date: 22 July 2016

Revised Date: 8 February 2017

Accepted Date: 8 February 2017

Please cite this article as: Wright, A.J., Edwards, R.J., van de Plassche, O., Blaauw, M., Parnell, A.C., van der Borg, K., de Jong, A.F.M., Roe, H.M., Selby, K., Black, S., Reconstructing the accumulation history of a saltmarsh sediment core: Which age-depth model is best?, Quaternary Geochronology (2017), doi: 10.1016/j.quageo.2017.02.004.

This is a PDF file of an unedited manuscript that has been accepted for publication. As a service to our customers we are providing this early version of the manuscript. The manuscript will undergo copyediting, typesetting, and review of the resulting proof before it is published in its final form. Please note that during the production process errors may be discovered which could affect the content, and all legal disclaimers that apply to the journal pertain. 
3 Alexander J. Wright ${ }^{a}$, Robin J. Edwards ${ }^{b_{*}}$, Orson van de Plassche ${ }^{\text {a }}$, Maarten Blaauw ${ }^{c}$, Andrew C.

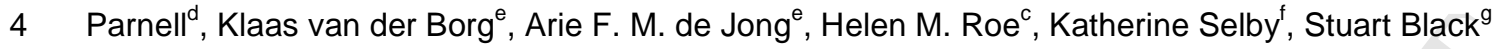

5 a Department of Marine Biogeology, Faculty of Earth \& Life Sciences, Vrije Universiteit Amsterdam, 61081 HV Amsterdam, the Netherlands.

$7 \quad$ b School of Natural Sciences, Trinity College Dublin, Dublin 2, Republic of Ireland.

Keywords: relative sea-level reconstruction; saltmarsh; age-depth model; Bayesian statistics 
Saltmarsh-based reconstructions of relative sea-level (RSL) change play a central role in current efforts seeking to quantify the relationship between climate and sea-level rise. The development of an accurate chronology is pivotal, since errors in age-depth relationships will propagate to the final record as alterations in both the timing and magnitude of reconstructed change. A range of age-depth modelling packages are available but differences in their theoretical basis and practical operation mean contrasting accumulation histories can be produced from the same dataset.

We compare the performance of five age-depth modelling programs (Bacon, Bchron, Bpeat, Clam and OxCal) when applied to the kinds of data used in high resolution, saltmarsh-based RSL reconstructions. We investigate their relative performance by comparing modelled accumulation curves against known age-depth relationships generated from simulated stratigraphic sequences. Bpeat is particularly sensitive to non-linearities which, whilst maximising the detection of small rate changes, has the potential to generate spurious variations, particularly in the last 400 years. Bacon generally replicates the pattern and magnitude of change but with notable offsets in timing. Bchron and OxCal successfully constrain the known accumulation history within their error envelopes although the best-fit solutions tend to underestimate the magnitude of change. The best-fit solutions of Clam generally replicate the timing and magnitude of changes well, but are sensitive to the underlying shape of the calibration curve, performing poorly where plateaus in atmospheric ${ }^{14} \mathrm{C}$ concentration exist.

We employ an ensemble of age-depth models to reconstruct a 1500 year accumulation history for a saltmarsh core recovered from Connecticut, USA based on a composite chronology comprising 26 AMS radiocarbon dates, ${ }^{210} \mathrm{~Pb},{ }^{137} \mathrm{Cs}$ radionuclides and an historical pollen chronohorizon. The resulting record reveals non-linear accumulation during the late Holocene with a marked increase in rate around AD1800. With the exception of the interval between AD1500 and AD1800, all models produce accumulation curves that agree to within $\sim 10 \mathrm{~cm}$ at the century-scale. The accumulation rate increase around AD1800 is associated with the transition from a radiocarbon-based to a ${ }^{210} \mathrm{~Pb}$ dominated chronology. Whilst repeat analysis excluding the ${ }^{210} \mathrm{~Pb}$ data alters the precise timing and magnitude of this acceleration, a shift to faster accumulation compared to the long-term rate is a robust feature of the record and not simply an artefact of the switch in dating methods. Simulation indicates that a rise of similar magnitude to the post-AD1800 increase (detrended increase of $\sim 16 \mathrm{~cm}$ ) 
50 is theoretically constrained and detectable within the radiocarbon-dated portion of the record. The

51 absence of such a signal suggests that the recent rate of accumulation is unprecedented in the last

521500 years. Our results indicate that reliable (sub)century-scale age-depth models can be developed

53 from saltmarsh sequences, and that the vertical uncertainties associated with them translate to RSL

54 reconstruction errors that are typically smaller than those associated with the most precise 55 microfossil-based estimates of palaeomarsh-surface elevation. 


\section{Introduction}

Constructing an accurate accumulation history is a vital but non-trivial component of most sedimentbased palaeoenvironmental reconstructions (Telford et al., 2004; Blaauw and Heegaard, 2012). This is exemplified by the current generation of 'high resolution' relative sea-level (RSL) studies seeking to employ saltmarsh sediments as late Holocene 'tide gauges' (see Barlow et al., 2013). In this approach the age and altitude of palaeomarsh-surfaces (PMS) (Figure 1a) are combined with estimations of the height above sea level at which they formed (Figure 1b) in order to reconstruct the RSL change experienced at a study site (Figure 1c). Microfossils such as foraminifera are used to infer PMS height whilst age control is provided by AMS radiocarbon dating of saltmarsh plant remains. Whilst some microfossil samples are directly dated, the age of others must be inferred by interpolation between dated horizons. Although this situation is not unique to RSL reconstruction, establishing an accurate age-depth relationship is particularly important for saltmarsh-based studies since it directly impacts the magnitude of the reconstructed change as well as determining its timing (see Figure 1c and 1d). As core collection typically targets high marsh environments, the resulting RSL reconstruction is primarily controlled by the sediment accumulation history (Edwards, 2007).

In recent years, several software tools have been developed to assist in the process of chronology construction. Whilst some packages employ classical statistical methods to develop age-depth models (e.g. Clam: Blaauw, 2010), the use of Bayesian statistics has become increasingly common (Parnell et al., 2011; Parnell and Gehrels, 2015). Variations in underlying theory and its practical application mean that each model handles data differently and, in this way, a single dataset can produce a diversity of accumulation histories. In fact, Blaauw and Heegaard (2012) note that model choice is the greatest source of uncertainty in age-depth modelling. Previous work highlights that each modelling approach has particular strengths and weaknesses, with no single model outperforming all others in every situation (Parnell et al., 2011). Consequently, comparative assessment of model performance using simulated and real data is an important step to ensure that informed choices are made during chronology construction (e.g. Telford et al., 2004; Blockley et al., 2007). Furthermore, since inaccurate accumulation histories can give rise to spurious RSL signals, it is important to ensure that any inferred rate changes are not simply artefacts of the calibration process or switches between dating method (Gehrels et al., 2005; Barlow et al., 2013). 
In this paper we present a new, well-dated saltmarsh sediment core from Connecticut, USA, covering the last 1500 years which is typical of sequences targeted in 'high resolution' RSL studies (e.g. Kemp et al., 2011, 2013). We use a suite of simulations to evaluate the performance of five age-depth modelling packages (Bacon, Bchron, Bpeat, Clam and OxCal) in order to address the following questions: 1) Do age-depth models introduce spurious accumulation rate changes?; 2) Can we tell if recent accumulation rates are without precedent given down-core changes in dating approach and resolution?

\section{Saltmarsh core and age data}

A 1.82 m-thick sequence of high saltmarsh peat was recovered from Pattagansett River marsh in Connecticut, USA (Figure 2). Twenty-six samples for AMS radiocarbon dating were collected at $6 \mathrm{~cm}$ intervals below $29 \mathrm{~cm}$ depth to produce a 1500 year-long record with an average of one radiocarbon date every 60 calendar years (Figure 3, Table B.1). This radiocarbon-based chronology was supplemented by pollen and short-lived radionuclide data from the upper $64 \mathrm{~cm}$ of the sequence (Figure 4, Table 1, Table B.2).

An initial manual wiggle-match of the radiocarbon data to the calibration curve (van de Plassche et al., 2001) confirms the predominantly linear nature of the age-depth profile and the absence of significant hiatuses (Figure 3). This is supported by the lithostratigraphy (Figure 2c) which indicates consistent accumulation within a high marsh environment (abundant Spartina patens rhizomes with uniform $\delta^{13} \mathrm{C}$ signatures (Table B.1)). The resulting late Holocene accumulation rate of $1.1 \mathrm{~mm} / \mathrm{yr}$ matches estimates of the underlying rate of glacio-isostatic adjustment $(\mathrm{GIA})$ for the region $(1.0 \pm 0.2 \mathrm{~mm} / \mathrm{yr}$, Donnelly et al., (2004); $1.1 \pm 0.1 \mathrm{~mm} / \mathrm{yr}$, Engelhart et al., (2009)), implying that the effects of sediment compaction in this shallow core are negligible. Forward extrapolation of this long-term rate fails to intersect with the modern surface by $\sim 13 \mathrm{~cm}$ (Figure 3b, 4f), indicating that an increase in accumulation rate must have occurred in the most recent portion of the record. This inference is confirmed by both a simple linear interpolation from the core top to the Ambrosia chronohorizon (mean accumulation rate of $1.7 \mathrm{~mm} / \mathrm{yr}$ since $\mathrm{AD} 1650$ ) or from the ${ }^{210} \mathrm{~Pb}$ and ${ }^{137} \mathrm{Cs}$ data (mean accumulation rates of $2.1 \mathrm{~mm} / \mathrm{yr}$ since AD1850 or $2.6 \mathrm{~mm} / \mathrm{yr}$ since AD1963). The local rate of RSL rise recorded by the tide gauge at New London is $2.3 \mathrm{~mm} / \mathrm{yr}$ since AD1938. 
113 Whilst this simple approach of comparing linear trends is sufficient to identify the existence of a recent 114 acceleration in saltmarsh accumulation rate, it cannot reliably quantify it given the range of possible 115 rates $(1.6 \mathrm{~mm} / \mathrm{yr}-2.8 \mathrm{~mm} / \mathrm{yr})$, or unequivocally date the timing of its onset. More importantly it is 116 unable to address the question of whether a change of similar magnitude occurred in the earlier, radiocarbon-dated portion of the record, which is masked within the larger age error envelope.

118 Age-depth modelling has been used to refine the timing and significance of recent changes identified in RSL records and to decrease the magnitude of age error envelopes by considering the stratigraphic ordering of dates within a sediment core (e.g. Kemp et al., 2011). However, given the differences in performance and underlying theory, it is unclear which approach will produce the most precise and accurate accumulation history for a particular sediment core. In the following section, we use simulations to produce a series of known accumulation histories against which we can evaluate the performance of the different age-depth modelling packages. Whilst numerous permutations of synthetic data are possible (e.g. uneven sampling intervals, varying age precision etc), the characteristics of the simulated dataset will influence relative model performance. Consequently, we develop a series of synthetic dates that emulate the sampling resolution and dating precision of the Pattagansett core chronology.

\section{Age-depth simulation and modelling}

\subsection{Developing synthetic sedimentary sequences}

We develop hypothetical age-depth scenarios to serve as targets for the chronological modelling programs (Figure 5, Appendix A). We initially consider a linear age-depth profile (Simulation 1) reflecting constant accumulation at a rate of $1.1 \mathrm{~mm} / \mathrm{yr}$ (the long-term linear rate of the Pattagansett core). We simulate the process of radiocarbon-based chronology construction by 'sampling' a hypothetical core at $6 \mathrm{~cm}$ depth intervals and then 'decalibrating' the known calendar age to a radiocarbon date. We follow the method of Michczyński (2007) which uses the calibration curve to convert a calendar age into a radiocarbon age which is then assigned an error term to emulate a radiocarbon date. We use an error term of \pm 35 yrs thereby producing a synthetic dataset of comparable resolution and precision to the Pattagansett record (Figure 5a). Finally, we include two age markers (along with the core-top) to simulate the provision of the age constraints provided by pollen and short-lived radionuclide data. 
142 We then explore the reconstruction of variable accumulation rates (Simulations 2-6) by superimposing 143 an oscillating (sinusoidal) term upon the background linear rise (Figure 5b, Figure 5c, Appendix A).

144 We vary the amplitude and the period of this oscillating term whilst ensuring sediment age increases consistently with depth in core. The magnitudes of the detrended oscillations range from $6-21 \mathrm{~cm}$

146

147 (Table A.1); the former being the smallest theoretically detectable signal based on our sampling resolution and the latter being the largest possible oscillation that does not violate the principle of superposition. A sinusoidally oscillating term is selected for operational simplicity and is not intended to imply that 'real' RSL oscillations are necessarily periodic. Instead, we use multiple simulations to gauge the capacity of different models to reliably capture non-linear changes of varying magnitude. We present these data as detrended signals since this is the format commonly used for comparison with models and between regions with differing background rates of RSL rise (e.g. Engelhart et al., 2009; Gehrels, 2010; Kemp et al., 2011; Barlow et al., 2014; Kopp et al., 2016).

\subsection{Age-depth models}

The synthetic data are processed by five age-depth modelling packages that are freely available and can be run on a desktop computer. Four of these programs (Bacon: Blaauw \& Christen, 2011; Bchron: Haslett \& Parnell, 2008; Bpeat: Blaauw \& Christen, 2005; Clam: Blaauw, 2010) are written for the free, open-source statistical environment R ( $R$ Development Core Team, 2010), whilst OxCal (Bronk Ramsey, 1995, 2001, 2009a) is a stand-alone package that can be run on-line or downloaded (c14.arch.ox.ac.uk). Clam (Blaauw, 2010) employs classical age-depth modelling, provides both numerical best-fit and confidence interval interpolations and was developed as a quick and transparent way to produce age-depth models. The remaining programs employ a Bayesian statistical approach which accommodates the introduction of additional 'prior' information to assist in refining the probability distributions of age data (see Parnell et al., 2011 for a review). For example, applying the principle of superposition means that models do not produce accumulation histories with age reversals and confidence intervals become narrower.

Bpeat (Blaauw \& Christen, 2005) provides numerical best-fit interpolations, graphical grey-scale summaries of uncertainty, and essentially functions as an advanced form of 'wiggle match dating'. Bacon (Blaauw \& Christen, 2011) provides numerical best-fit and confidence interval interpolations, graphical grey-scale summaries of uncertainty, and is superficially similar to Bpeat in terms of its tuneable parameters (see Appendix A). Bchron (Haslett \& Parnell, 2008) provides numerical best-fit 
172

173

174

175

176

177

178

179

180

181

182

183

184

and confidence interval interpolations and is fully automated so does not require extensive preliminary analysis to determine optimal parameters. Finally, OxCal (Bronk Ramsey, 1995, 2001, 2008, 2009a; Bronk Ramsay and Lee, 2013) provides numerical confidence interval interpolations but no best-fit solution. It also has additional functionality in the manner in which outliers are identified during agedepth modelling (Bronk Ramsey, 2009b).

Further details of the theoretical basis and operation of each of the models are provided in the publications that accompany them and useful comparative reviews of a subset of packages have been made by Blockley et al. (2007) and Parnell et al. (2011). Whilst the number of model development runs $(>100)$ means the details cannot be presented here, we summarise the key outcomes of these analyses, and document the selection of parameters where they deviate from the default values (Appendix A). The nature of the models (e.g. use of Monte Carlo sampling) means that results may vary slightly between runs made with identical settings. Consequently, during model evaluation and development, we considered the output from multiple runs, and present results as the mean of three runs per reconstruction. The final selection of parameters (Table 2) was made to optimise the fit between model output and the suite of simulated curves, whilst ensuring choices were parsimonious and avoided over-fitting (Blaauw \& Heegaard, 2012).

We assess the performance of these models by comparing the accuracy and precision of the detrended profiles. We measure accuracy in terms of how closely a best-fit model solution approximates the target accumulation history, and the extent to which this known curve is contained within the error envelope of the reconstruction. The magnitude of the error envelope is used to indicate model precision, and hence increased model precision must be accompanied by better model fit if the reconstruction is still to be deemed accurate. Quantitative measures of overall goodness-of-fit are included in Table A.2.

\subsection{Modelling linear accumulation}

Figure 6 presents the detrended accumulation histories produced by each of the modelling programs for the linear age-depth scenario. Since accumulation is constant throughout, any deviation from a horizontal line indicates the potential for spurious rate changes to be introduced during the calibration and interpolation process. 
In general, we consider all models to have accurately reconstructed the linear accumulation scenario in that the best-fit curves do not deviate substantially from a straight line (misfits $<5 \mathrm{~cm}$ ), and the real profile is always contained within the confidence intervals (Figure 6a, Figure 6b). This is an important result as it demonstrates that reconstructions produced by any of these programs do not produce spurious oscillations linked to the underlying structure of the radiocarbon calibration curve (see Gehrels et al., 2005; Gehrels \& Woodworth, 2013; Barlow et al., 2013), at least not when based on the kind of well-dated sequence considered here.

Small differences in model reconstructions do arise indicating variations in their sensitivity to calibration curve shape. The best-fit curves of Bpeat and Clam are most susceptible to this effect during the last 400 years of the record and the wide Clam confidence intervals indicate reduced precision at certain points, equivalent to age uncertainties of up to $\sim 150$ years (Figure $6 \mathrm{~d}$ ).

\subsection{Modelling non-linear accumulation}

Non-linear scenarios reveal the potential for real rate changes to be distorted or masked within a predominantly radiocarbon-dated sequence. We begin by considering a signal of $\sim 21 \mathrm{~cm}$ (Simulation 6, Table A.1) which is of comparable magnitude to the recent (c. 100-200 yrs) detrended increase in RSL rise reported from the Atlantic coast of North America (e.g. Gehrels, 2010; Kemp et al. 2011).

Figure 7 presents the simulated accumulation curve along with the reconstructed curves produced by the various programs. We initially compare model performance by asking three questions: 1) Does the model consistently detect accumulation rate change? 2) Does the model accurately represent the magnitude of change? 3) Does the model reliably reproduce the pattern of change?

All models unambiguously detect the accumulation rate changes and this is clearly reflected in both the best-fit solutions and confidence intervals (Figure 7a, Figure 7b). The magnitude of change is excellently reproduced by the best-fit reconstructions of Bpeat. The best-fit curves for Clam and Bacon reliably capture the magnitude of some oscillations, but are not consistent throughout the sequence, encountering particular difficulties in the last few hundred years of the record. The best-fit solution of Bchron consistently underestimates the peak magnitude of change.

The nature of the Bpeat program means that the oscillating curve is essentially represented by a series of linear segments. Whilst these do an excellent job of approximating the upward limb of each oscillation, the falling limbs appear as isolated or disjointed collections of points, effectively 
229

230

231

232

233

234

235

236

237

238

239

240

241

242

243

244

245

246

247

248

249

250

251

252

253

254

255

256

257

resembling hiatuses that correlate with phases of extremely low or zero accumulation. These falling limbs are associated with significant age misfits (Figure 7e). Whilst the best-fit curve for Clam does a good job of replicating the pattern of change for the earlier oscillations, the narrow confidence intervals associated with its reconstructions do not always circumscribe the actual accumulation curve, and consequently may give the impression of false precision. The difficulties encountered in the last few hundred years, reflecting the underlying structure of the radiocarbon calibration curve, are also evident as larger confidence intervals that still do not always contain the real accumulation history (Figure 7b).

Whilst Clam and Bacon indicate broadly similar magnitudes of change, there is a phase offset in the Bacon reconstruction which results in a tendency for both the best-fit curve and the confidence intervals to lead the real accumulation curve. This produces large misfits (particularly for age) and the appearance of poorer overall performance (Figure 7e), even though the general shape of the confidence intervals are a reasonable approximation of the underlying signal. This temporal offset may be linked to the use of a sinusoidal term (e.g. an aliasing effect), or may reflect our choice of 'section thickness' in the Bacon setup (Appendix A). Irrespective of the precise cause, these betweenmodel differences are indicative of the kinds of temporal uncertainty associated with model choice and the reconstruction process, even where all models employ data with the same sampling frequency. In this instance, whilst inter-model differences are typically of the order of c. 50 years, they may rise to a century or more (Figure 7e). Overall, Bchron and Oxcal outperform the other programs in terms of their ability to reliably capture known accumulation variability within their confidence intervals (Figure 7b).

To explore further the issue of signal detectability we repeat the process using a series of simulations with oscillations of differing magnitude (Table A.1, Appendix A). These results indicate that the ability to consistently detect rate changes begins to fail with oscillations $\sim 10 \mathrm{~cm}$ in magnitude (i.e. Simulation 3). For example whilst Bpeat identifies the existence of every oscillation, it fails to reliably capture the magnitude of every change (Figure A.10c). Although none of the other best-fit solutions accurately reflect this scale of oscillation, the confidence intervals of Bchron and OxCal continue to perform well by circumscribing the actual accumulation curve and providing indications of its non-linear form (Figure A.13c, Figure A.14c). 
Figure 8 shows a simulated curve with oscillations of $\sim 13 \mathrm{~cm}$ (Simulation 4) which are comparable in magnitude to the recent increase in accumulation recorded in the Pattaganssett record (Figures 3 \& 4). All models recognise the existence of the oscillations, with the best-fit curve for Bpeat most closely approximating their magnitude (Figure 8a). In this instance, the best-fit curve of Clam outperforms that of Bacon which has become somewhat unstable, perhaps linked to the greater significance of phaseshifts in a scenario with shorter period oscillations (Figure 8c). Once again, whilst the best-fit solution for Bchron underestimates the magnitude of change, both its confidence intervals, and those of OxCal, do a good job of delimiting the target accumulation curve (Figure 8b).

Collectively, these results demonstrate an accumulation signal of $\sim 21 \mathrm{~cm}$ (Simulation 6 ), comparable to the increases in RSL rise reported from other sites along the Atlantic coast of USA, will be detectable within the radiocarbon-dated portion of the record irrespective of the age-depth modelling program employed (Figure 7). Conversely, signals with a magnitude of less than $\sim 10 \mathrm{~cm}$ (Simulation 3) will likely be circumscribed by the confidence intervals (Figure A.3c) but may not be accurately resolved by a best-fit solution (Figure A.2c) given the quality of the data, vertical sampling interval and the underlying background accumulation rate.

Whilst the choice of modelling program influences the detail of the final best-fit accumulation curve, differences between models only translate to centimetre-scale vertical discrepancies in their reconstructions (Figure A.7). These offsets are generally small when compared to the size of the confidence intervals associated with each model. As the lower limits of signal detection are approached, inter-model differences tend to become more pronounced with different models 'failing' in contrasting ways. An important exception to this general pattern is the relatively poor performance of all models in the last 400 years of the record reflecting the underlying shape of the radiocarbon calibration curve. Whilst vertical offsets may be subtle, misfits in the reconstructed timing of changes can be of the order of a century or more.

\section{Developing an age-depth model for the saltmarsh core}

283 The simulations presented in Section 3 are tailored to exploring model performance when applied to a dataset with a radiocarbon-dating precision ( $\pm 35 \mathrm{yrs}$ ) and effective sampling resolution ( 1 date every c. $60 \mathrm{yrs}$ ) comparable to our Connecticut saltmarsh core (Section 2). These provide information on 
287

288

289

290

291

292

293

294

295

296

297

298

299

300

301

302

303

304

305

306

307

308

309

310

311

312

313

314

315

portion of our record ( $\sim 13 \mathrm{~cm}$ or more). Oscillations smaller than this may be constrained within the confidence intervals but will not be accurately discernible in envelope shape or associated best-fit curves. Subtle changes of $\sim 5 \mathrm{~cm}$ are equivalent to the misfits associated with modelling linear accumulation and so can effectively be regarded as indistinguishable from 'noise'.

In light of the differences in performance outlined in Section 3, we employ an ensemble of age-depth models to utilise the relative strengths of the different approaches and infer additional information from the discrepancies between reconstructions. We exclude Bacon from this analysis due to the 'phase-shift' effect noted in simulation (Section 3.4).

Applying Occam's razor (and in the absence of evidence to the contrary) the assumption of a linear accumulation rate is a reasonable starting place for chronological model development. More complicated accumulation histories only need be invoked when this linear assumption fails to adequately describe the data. The sensitivity of Bpeat to non-linearity (Section 3.3) makes it an excellent first-assessment tool. If Bpeat suggests limited divergence from a linear profile, we can be confident that we are not missing any significant rate changes. Where Bpeat does identify potential rate changes, we can use the best-fit solution to provide an indication of their likely location, and to get an approximate magnitude of the detrended signal involved. The cost of this sensitivity is that Bpeat has the greatest potential to produce spurious 'jumps' where none exist, notably around the c. AD1700 'threshold' in the calibration curve (e.g. Figure 6a).

Once this initial framework is in place, Bchron or OxCal can be used to provide confidence intervals on the basis that they consistently circumscribe the simulated accumulation curve (Section 3.4). Whilst the extremes of these confidence intervals will tend to overestimate the magnitude of an actual oscillation (Figure 8b), the best-fit solution of Bchron has a tendency to smooth or dampen the oscillation (Figure 8a), with this becoming more pronounced as dating precision reduces. Therefore as a final step, it may be instructive to consult the best-fit solution of Clam since this tends to provide a middle-ground reconstruction against which the extremes of Bpeat and Bchron/OxCal can be evaluated, particularly in the earlier (pre-AD1600) portion of the record (Figure 8e).

\subsection{Evaluating the model ensemble}

The initial screening run using Bpeat provides strong evidence for non-linear accumulation within the record (Figure 9a). Changes in the early portion of the sequence are small $(\sim 5 \mathrm{~cm})$ and therefore 
below the limit of reliable detection inferred from simulation. More marked variation is apparent after

317 AD1500 with a reduction in rate, followed by a short interval of quasi-uniform accumulation before the most recent acceleration commenced around AD1800. Whilst this pronounced oscillation (detrended rise of $26 \mathrm{~cm}$ ) is much larger than anything experienced during the preceding millennium, simulations indicate that Bpeat 'failure' may overestimate the magnitude of change during this time interval (Figure 8a, Figure 8c).

Adding the Bchron / OxCal confidence intervals and best-fit solution refines the initial accumulation history outlined by Bpeat (Figure 9b), constraining the maximum size of any pre-AD1500 detrended change to $\sim 13 \mathrm{~cm}$ or less and placing the c. AD1800 rise between $\sim 9$ and $18 \mathrm{~cm}$. Both the confidence intervals and the best fit solution (Bchron) indicate pre-AD1500 oscillations that are larger than any artefacts noted in the linear simulation (Figure 6), suggesting they are real features of the record. The post-AD1500 rate reduction is essentially absent from the Bchron / Oxcal reconstructions and so the subsequent detrended rise is correspondingly smaller. This more muted picture of change is consistent with the tendency for the Bchron best-fit curve to smooth variability evident in the simulations (Figure 8a).

Finally, the best-fit curve of Clam reconstructs oscillations in the pre-AD1500 portion of the record which equate to a detrended signal of $\sim 12 \mathrm{~cm}$ and are generally contained within the Bchron / Oxcal confidence intervals (Figure 9c). The only departure from this pattern is following the post-AD1500 deceleration when the curve plots just below the confidence intervals between AD1600 and AD1800, giving a detrended recent rise of $\sim 21 \mathrm{~cm}$.

\subsection{Model sensitivity to age data selection}

To investigate the effect of a switch in dating method, we repeat the age-depth model runs for our saltmarsh core with the ${ }^{210} \mathrm{~Pb}$ data removed (Figure 10b). The impact of this change on the best-fit reconstructions is minimal for Bchron and Clam, whilst its effect on Bpeat is to shift the major inflection in accumulation rate from AD1800 to AD1700. In contrast a marked post-AD1700 impact is

341 seen in the confidence intervals of OxCal and Bchron, the latter of which in particular expands significantly until constrained by the ${ }^{137} \mathrm{Cs}$ marker.

343 The difference in behaviour between Bpeat, Bchron and Clam can be attributed to the manner in which they incorporate the pollen chronohorizon data and use it to constrain which side of the 
345 AD1650 horizon contemporaneous radiocarbon dates are placed (Figure 3b). To illustrate this effect, 346 we repeat our analysis with the pollen chronohorizon also removed (Figure 10c). The best-fit solutions 347 of Bchron and Clam are not significantly affected, and there is no substantial further expansion of the 348 Oxcal and Bchron confidence intervals. In contrast, the best-fit solution of Bpeat alters dramatically, 349 effectively smoothing out the large post-AD 1500 rate reduction and producing a reconstruction that 350 approximates that of Bchron. It is interesting to note that removal of this age constraint produces a 351 less 'rigid' reconstruction in the earlier portion of the record, with Bpeat now closely tracking the 352 Bchron best-fit solution and adding further support for non-linear change prior to AD1500.

353 As a final illustration of sensitivity, we remove the radiocarbon date at $65 \mathrm{~cm}$ depth (adjacent to the 354 pollen chronohorizon) which plots as a potential outlier in the original linear 'wiggle-match' (Figure 3a). 355 Whilst the best-fit curve of Bchron is not significantly impacted, the Clam and Bpeat reconstructions 356 more closely align and the best-fit curves plot close to that of Bchron for the period AD1500-1600 357 (Figure 10d). Collectively, these model runs indicate that Bchron and Oxcal produce the most 'stable' reconstructions and that as data are removed the best-fit solutions of Bpeat and Clam tend to converge toward that of Bchron.

\subsection{Towards a 'consensus' accumulation curve}

We combine these reconstructions to develop an informal 'consensus' accumulation curve (Figure 10e). With the exception of the period between AD1500 and AD1800, all models show excellent agreement (within $\sim 5 \mathrm{~cm}$ of each other). Our consensus curve is constrained within the Bchron and Oxcal confidence intervals, respects all points where the individual age-depth profiles overlap, and remains within $\sim 10 \mathrm{~cm}$ of all best-fit solutions. For the interval centred on AD800, our curve approximates the best-fit solution of Bchron on the basis that Bpeat does not register a large oscillation at this point. Between AD1000 and AD1300 our curve closely tracks the best-fit solution of Clam on the basis that a rate reduction is evident in all models whilst simulation results suggest the best-fit solution of Bchron is likely to smooth this signal. Between AD1300 and AD1400, the best-fit solutions of all models are essentially indistinguishable and show an accelerated rate of rise which is also mirrored in the confidence interval trends. Whilst the small magnitude of this signal $(\sim 5 \mathrm{~cm})$ is below the reliable limits of detection indicated by simulation, the agreement between models suggests that an accelerated rate of rise sometime during the $13^{\text {th }}$ and $14^{\text {th }}$ centuries is likely, although its magnitude cannot be accurately determined. 
375 After AD1400, the best-fit solutions begin to diverge and our consensus curve initially tracks that of 376 Clam and Bpeat on the basis of the smoothing-tendency associated with Bchron. The consensus 377 curve then diverges from both that of Bpeat and Clam and instead tracks the lower limit of the Bchron and Oxcal confidence intervals. This solution is selected on the basis that simulations indicate Bpeat and Clam are prone to producing spurious signals in this time interval, whilst the combined confidence intervals of Bchron and Oxcal consistently circumscribe the target curves during simulation. In effect, it produces a best-fit solution that lies midway between the extremes of Bchron and Bpeat. From AD1800 onward the best fit solutions converge as they enter the more tightly constrained portion of the chronology, and are essentially indistinguishable during the $19^{\text {th }}$ and $20^{\text {th }}$ centuries. An inflection centred around AD1800 is clear in all chronologies, as is the stepped nature of the final portion of the curve with a brief slowdown centred on AD1900 interrupting the accelerated rate of the last 200 years.

\subsection{Are recent accumulation rates unprecedented?}

It is clear that the upper portion of our core from Pattagansett, which post-dates AD1800, accumulated faster than the background rate experienced over the last 1500 years. The detrended magnitude of this recent rise is between $\sim 9-26 \mathrm{~cm}$ (equivalent to accumulation rates of $1.6-2.4$ $\mathrm{mm} / \mathrm{yr}$ ) although the results of simulation suggest that these extremes are likely under- and overestimates of the real signal. Instead, the consensus 'best-fit' curve places the rise at $\sim 16 \mathrm{~cm}$ which, whilst equivalent to a century-scale accumulation rate of $\sim 1.9 \mathrm{~mm} / \mathrm{yr}$, includes an interval of reduced rate centred around AD1900. This accords well with the accumulation rates inferred by simple linear interpolation of the pollen and short-lived radionuclide data (Table 1).

The simulation results indicate that a signal of $16 \mathrm{~cm}$ would be accurately resolved in the radiocarbondated portion of the record. Whilst it is possible that an oscillation of up to $\sim 13 \mathrm{~cm}$ could be accommodated within the confidence intervals of the accumulation curve prior to AD1800, simulations indicate that these intervals tend to overestimate the magnitude of change. This fact, coupled with the limited response of Bpeat which simulations show to be sensitive to non-linearities, suggests that a pre-AD 1800 signal of the order of $\sim 10 \mathrm{~cm}$ or less is the most plausible interpretation of the data. On this basis, we conclude that accumulation during the last two centuries occurred at a century-scale rate that is without precedent in the previous 1300 years of the record. 
Similar accelerations in accumulation rate (translated into increases in the rate of RSL rise) have been documented in a number of saltmarshes around the globe (Kemp et al. 2009, 2011; Gehrels \& Woodworth, 2013). Whilst simulations like those presented here would be needed to determine if the noted increases are larger than any signal that could be masked within the age-depth uncertainties particular to each record, our results provide support for the contention that recent rates of RSL rise along parts of the Atlantic coast of $\mathrm{N}$. America are without precedent for much of the Common Era (e.g. Kemp et al., 2013, 2015; Kopp et al., 2016). In their synthesis sea-level reconstructions, Kopp et al. (2016) conclude that global sea level variability over the pre- $20^{\text {th }}$ century Common Era was smaller than the $\pm 25 \mathrm{~cm}$ estimated in the IPCC fifth assessment report (Mason-Delmotte et al., 2013) and instead was very likely to be between $\sim \pm 7 \mathrm{~cm}$ to $\sim \pm 11 \mathrm{~cm}$. Our simulations indicate that even the smaller of these signals (ie a $14 \mathrm{~cm}$ 'oscillation') would be detectable if expressed as an accumulation rate change in a well-dated saltmarsh core with similar properties to our material from Pattagansett.

Geological data are required to extend the duration of instrumental records in order to address topical questions relating to the timing, magnitude, spatial pattern and significance of sea-level change (Gehrels 2010; Mason-Delmotte et al., 2013; Miller et al., 2013). Saltmarsh sediments have attracted particular interest due to the fact that they can furnish near-continuous, (sub)centennial- and decimetre-scale records that overlap with tide gauge data and extend back many centuries into the past. Proxy records that are precise enough to permit meaningful comparison with tide gauges are at the limits of resolution, both of the methodologies employed to develop them, and of the sedimentary archives from which they are extracted (Edwards, 2007). Consequently, whilst the use of saltmarshes as geological tide gauges is now an established technique, its application requires detailed knowledge of the sediments and the proxies employed, and careful consideration of the uncertainties associated with reconstructions of age and altitude (Gehrels \& Shennan, 2015; Shennan, 2015).

Barlow et al. (2013) highlight the need to evaluate age models and suggest that particular caution is required when interpreting $R S L$ changes that may reflect the underlying structure of the radiocarbon calibration curve, or which coincide with the junction between chonological methods. The results of our simulations and the comparative application of multiple age-depth modelling approaches permit 
432

433

434

435

436

437

438

439

440

441

442

443

444

445

446

447

448

apply to well-dated sequences such as our Pattagansett core which is devoid of any significant hiatuses.

Firstly, whilst simple interpolation of radiocarbon data does have the potential to introduce spurious rate changes that mirror the calibration curve (Gehrels et al., 2005), our linear simulations demonstrate that when dealing with a well-dated sequence, all of the age-depth modelling approaches we consider are not significantly influenced by this phenomenon.

Secondly, by necessity, all chronologies that cover the intersection between instrumental and geological data will be derived from a composite of chronological methods. The fact that the junction between ${ }^{210} \mathrm{~Pb}$ and ${ }^{14} \mathrm{C}$ records is coincident with the timing of a potentially significant rate change means that simply extrapolating and comparing two linear trends is prone to error. However, since the age-depth models take into consideration age uncertainties, there is no a priori reason that a switch in dating approach will result in a marked rate change in best-fit solutions. Instead, the shift in resolution and precision will be expressed as a change in the width of confidence intervals as is clearly illustrated by the reconstructions from Pattagansett (Figure 10). Hence, whilst the most significant rate change of our 1500 year record occurs close to the boundary between dating approaches, it is not an artefact of this switch in chronometers.

Whilst the presence of an acceleration is a robust feature of our record, the exact magnitude and timing of the change, and the precision with which it can be established, are influenced by the ${ }^{210} \mathrm{~Pb}$ data, the supporting chronological information provided by the pollen chronohorizon and the choice of modelling program employed. In our example, the post-AD1800 detrended accumulation rate ranged from $1.6-2.4 \mathrm{~mm} / \mathrm{yr}$ depending on which age-depth model was selected, and this uncertainty exists before accounting for additional error terms that ultimately influence a RSL reconstruction (e.g. underlying GIA rate, PMS height reconstruction etc). Similarly, age-misfits varied between models when applied to simulated data with a resolution / precision comparable to our saltmarsh core (Figure 7e, Figure A.4, Figure A.5). Encouragingly errors were typically less than $~ 50$ years for much of the record, but could rise to a century or more at certain points, with no modelling program being completely immune to this effect which reflects the underlying shape of the calibration curve. This is noteworthy since there is particular interest in trying to pin-point the timing of any recent acceleration in the rate of RSL rise with a view to better understanding the drivers and mechanisms responsible (e.g. Gehrels \& Woodworth, 2013; Long et al., 2014; Kopp et al. 2016). 
462 Gehrels \& Woodworth (2013) attempt to distil this kind of detailed information from seven saltmarsh 463 records but choose to exclude all data points that are not directly dated on the basis that age-depth 464 modelling can introduce spurious signals. This conservative approach was justified given that only two 465 of the sites possessed sequences with sufficiently well-constrained chronologies to produce the kinds 466 of records described above. This limitation exists despite the records being a carefully selected sub467 set of the available data, chosen on the basis of their comparatively high quality. This reinforces the 468 fact that the chronological requirements for the use of saltmarsh sequences as geological tide gauges 469 are extremely exacting and have rarely been met for practical reasons such as cost of analysis and access to suitable sedimentary sequences. For example, irregularly spaced dates, changes in the 471 type of dated material and sequences with varied lithology, all present additional challenges when age-depth modelling. Simulations such as those performed here, using synthetic data designed to emulate the characteristics of the sedimentary sequences of interest, are useful exploratory tools for assessing model performance and gauging record resolution.

Whilst a comprehensive assessment of all these variables is beyond the scope of this paper, we briefly examine the influence of dating precision by repeating our simulations using synthetic radiocarbon dates with ${ }^{14} \mathrm{C}$ age errors of \pm 70 years, comparable to radiocarbon dates reported in some of the older saltmarsh literature (e.g. Nydick et al., 1995) and \pm 10 years, similar to the pooled high precision AMS dates of some more recent work (e.g. Kemp et al., 2009). The results are illustrated in Figure 11 for an oscillation of $\sim 13 \mathrm{~cm}$ (Simulation 4). The best-fit solutions based on lower precision dates fail to reliably resolve the oscillation (Figure 11c) and the confidence intervals for all models are expanded yet do not always circumscribe the simulated curve (Figure 11f). In contrast, the high precision dates reduce confidence interval width (increased precision) whilst still generally constraining the simulated accumulation curve (retained accuracy). However, the depth and age misfits of the best-fit solutions are not significantly altered by the use of high-precision dates since they remain ultimately tied to the shape of the calibration curve. Instead, the use of complementary forms of chronological information, such as stable lead isotope or other dated pollution markers, will be required to further refine these chronologies (e.g. Gehrels et al., 2006, 2008; Kemp et al., 2012; Marshall, 2015). 
492 of the individual sediment core. For example, in regions of rapid RSL rise (e.g. high GIA-related 493 subsidence), the creation of accommodation space permits rapid sediment accumulation, resulting in 494 a higher temporal sampling resolution for a given down-core sampling interval. When considering an 495 oscillating RSL term, the background accumulation rate also determines the maximum size of 496 oscillation that can be accommodated before sediment over-printing occurs. Hence, in locations with 497 low background accumulation rates, the magnitude of the resolvable signal is reduced. Consequently, 498 the comparison of RSL records from regions of contrasting GIA, even following detrending, is not 499 always straightforward. Simulations using synthetic data tailored to the particular characteristics of 500 each record may prove useful tools for evaluating the significance of apparent inter-record 501 differences.

\section{5. Summary and conclusions}

503 The use of saltmarshes as geological 'tide gauges' requires the development of precise and accurate accumulation histories for the sediment cores used to furnish the proxy data. Advances in age-depth modelling coupled with detailed dating of sedimentary sequences using a combination of AMS radiocarbon, short-lived radionuclide and historical chronohorizon techniques, mean robust (sub)century-scale reconstructions are possible. Next generation RSL reconstruction methods will combine age-depth relationships and PMS estimates within a single numerical framework (e.g. Cahill et al., 2016), but the resulting reconstructions are still governed by the age-depth model choice. The importance of evaluating the performance of each module in the assembled hierarchical model increases with the complexity of data manipulation, as the direct connection between raw data and resulting reconstruction is obfuscated incrementally.

513 We compare the performance of five age-depth modelling programs through the use of simulation and 514 subsequent application to a real saltmarsh sediment core. On the basis of our results we conclude:

- Simulations constructed to emulate the sampling resolution and data quality of a real sedimentary record provide valuable insights into the relative performance of age-depth models, whilst indicating the smallest change that can theoretically be resolved;

- No single modelling package out-performs all others, but an ensemble approach can exploit different model strengths to produce a 'consensus' estimate of accumulation history; 
- In a well-dated sequence, inter-model differences in reconstruction are generally smaller than the error terms associated with them, and translate to vertical errors that are typically less than the uncertainties associated with microfossil-based PMS reconstruction;

- Age-depth modelling does not generate spurious oscillations related to the underlying structure of the radiocarbon calibration curve when applied to well-dated sequences such as our example core from Pattagansett River marsh, Connecticut, USA;

- Whilst the interval between AD1500 and AD1800 is particularly challenging for age-depth models based on radiocarbon dating, an increase in accumulation relative to the background rate is noted at Pattagansett and this is not an artefact generated by a switch between dating methods;

- Precisely delimiting the timing of the recent increase in accumulation rate is reliant on the provision of complementary (i.e. non-radiocarbon) age data, but the balance of evidence suggests marsh surface rose more during the last 200 years than at any other comparable period in this 1500 year-long record.

\section{ACKNOWLEDGEMENTS}

This work was supported by: the Dutch National Research Programme on Global Air Pollution and Climate Change (Ocean-climate variability and sea level in the North Atlantic region since AD 0); the Vrije Universiteit Amsterdam (Coastal Records); the European Union (Simulations, observations \& palaeoclimatic data: climate variability over the last 500 years) to OvdP. AW and RE wrote the manuscript. The Pattagansett core chronological data were provided by AdJ and KvdB (radiocarbon), $\mathrm{HR}$ and $\mathrm{KS}$ (pollen), and SB $\left({ }^{210} \mathrm{~Pb}\right)$. AP and MB provided assistance with age model runs (Bpeat, Clam, Bacon, Bchron). This paper is a contribution to IGCP Project 639, "Sea-level change from minutes to millennia". 
543

544

545

546

547

548

549

550

551

552

553

554

555

556

557

558

559

560

561

562

563

564

565

566

567

568

569

References

Appleby, P.G., 2001. Chronostratigraphic techniques in recent sediments. In: Last, W.M., Smol, J.P. (Eds.), Tracking Environmental Change Using Lake Sediments. Volume 1: Basin Analysis, Coring and Chronological Techniques Kluwer Academic Publishers, Dordrecht, The Netherlands, pp. 171-203.

Appleby, P.G., 2008. Three decades of dating recent sediments by fallout radionuclides: a review

$$
\text { 1. The Holocene 18, 83-93. }
$$

Barlow, N.L.M., Shennan, I., Long, A.J., Gehrels, W.R., Saher, M.H., Woodroffe, S. A., Hillier, C., 2013. Salt marshes as late Holocene tide gauges. Glob. Planet. Change 106, 90-110. doi:10.1016/j.gloplacha.2013.03.003

Barlow, N.L.M., Long, A.J., Saher, M.H., Gehrels, W.R., Garnett, M.H., Scaife, R.G., 2014. Salt-marsh reconstructions of relative sea-level change in the North Atlantic during the last 2000 years. Quat. Sci. Rev. 99, 1-16. doi: 10.1016/j.quascirev.2014.06.008

Blaauw, M., 2010. Methods and code for "classical" age-modelling of radiocarbon sequences. Quat. Geochronol. 5, 512-518. doi:10.1016/j.quageo.2010.01.002

Blaauw, M., Christen, J.A., 2005. Radiocarbon peat chronologies and environmental change Journal of the Royal Statistical Society Series C-Applied Statistics 54, 805-816.

Blaauw, M., Christen, J.A., 2011. Flexible Paleoclimate Age-Depth Models Using an Autoregressive Gamma Process. Bayesian Analysis 6, 457-474.

Blaauw, M., Heegaard, E., 2012. Estimation of Age-Depth Relationships. In H.J.B. Birks et al. (eds.), Tracking Environmental Change Using Lake Sediments. Developments in Paleoenvironmental Research 5. Springer. DOI 10.1007/978-94-007-2745-8 12

Blockley, S.P.E., Blaauw, M., Bronk Ramsey, C., van der Plicht, J., Blockley, S., 2007. Building and testing age models for radiocarbon dates in Lateglacial and Early Holocene sediments. Quat. Sci. Rev. 26, 1915-1926.

Bronk Ramsey, C., 1995. Radiocarbon calibration and analysis of stratigraphy: The OxCal program. Radiocarbon, 37(2), 425-430. 
570

571

572

573

574

575

576

577

578

579

580

581

582

583

584

585

586

587

588

589

590

591

592

593

594

595

596

Bronk Ramsey, C., 2001. Development of the radiocarbon calibration program OxCal. Radiocarbon, 43(2A), 355-363.

Bronk Ramsey, C., 2008. Deposition models for chronological records. Quaternary Science Reviews, $27(1-2), 42-60$.

Bronk Ramsey, C., 2009a. Bayesian analysis of radiocarbon dates. Radiocarbon, 51(1), 337-360.

Bronk Ramsey, C., 2009b. Dealing with outliers and offsets in radiocarbon dating. Radiocarbon, 51(3), 1023-1045.

Bronk Ramsey, C., Lee, S., 2013. Recent and Planned Developments of the Program OxCal. Radiocarbon, 55(2-3), 720-730.

Brugham, R.B., 1978. Pollen indicators of land-use change in Southern Connecticut. Quaternary Research, 9, 349-362.

Cahill, N., Kemp, A.C., Horton, B.P., Parnell, A.C., 2016. A Bayesian hierarchical model for reconstructing relative sea level: from raw data to rates of change. Clim. Past Discuss. 12.2, 525-542. doi:10.5194/cpd-11-4851-2015

Clark, J.S., Overpeck, J.T., Webb, T III, Patterson, W.A. III., 1986. Pollen stratigraphic correlation and dating of barrier-beach peat sections. Review of Palaeobotany and Palynology, 47, 145-168

Donnelly, J.P., 2004. Coupling instrumental and geological records of sea-level change: Evidence from southern New England of an increase in the rate of sea-level rise in the late 19th century. Geophys. Res. Lett. 31, 2-5. doi:10.1029/2003GL018933

Edwards, R., 2007. Sea levels: resolution and uncertainty. Prog. Phys. Geogr. 31, 621-632. doi:10.1177/0309133307087086

Engelhart, S.E., Horton, B.P., Douglas, B.C., Peltier, W.R., Tornqvist, T.E., 2009. Spatial variability of late Holocene and 20th century sea-level rise along the Atlantic coast of the United States. Geology 37, 1115-1118. doi:10.1130/G30360A.1

Gehrels, R., 2010. Sea-level changes since the Last Glacial Maximum: an appraisal of the IPCC Fourth Assessment Report. J. Quat. Sci. 25, 26-38. doi:10.1002/jqs.1273

Gehrels, W., Kirby, J., Prokoph, a, Newnham, R., Achterberg, E., Evans, H., Black, S., Scott, D., 
2005. Onset of recent rapid sea-level rise in the western Atlantic Ocean. Quat. Sci. Rev. 24, 2083-2100. doi:10.1016/j.quascirev.2004.11.016

Gehrels, W.R., Hayward, B.W., Newnham, R.M., Southall, K.E., 2008. A 20th century acceleration of sea-level rise in New Zealand. Geophys. Res. Lett. 35, 1-5. doi:10.1029/2007GL032632

Gehrels, W.R., Marshall, W.A., Gehrels, M.J., Larsen, G., Kirby, J.R., Eiriksson, J., Heinemeier, J., Shimmield, T., 2006. Rapid sea-level rise in the North Atlantic Ocean since the first half of the nineteenth century. The Holocene 16, 949-965. doi:10.1177/0959683606hl986rp

Gehrels, W.R., Shennan, I., 2015. Sea level in time and space: revolutions and inconvenient truths. J. Quat. Sci. 30, 131-143. doi:10.1002/jqs.2771

Gehrels, W.R., Woodworth, P.L., 2013. When did modern rates of sea-level rise start? Glob. Planet. Change 100, 263-277. doi:10.1016/j.gloplacha.2012.10.020

Haslett, J., Parnell, A., 2008. A simple monotone process with application to radiocarbon-dated depth chronologies. Journal of the Royal Statistical Society Series C-Applied Statistics 57, 399-418

Kemp, A.C., Hawkes, A.D., Donnelly, J.P., Vane, C.H., Horton, B.P., Hill, T.D., Anisfeld, S.C., Parnell, A.C., Cahill, N., 2015. Relative sea-level change in Connecticut (USA) during the last $2200 \mathrm{yrs}$. Earth Planet. Sci. Lett. 428, 217-229. doi:10.1016/j.epsl.2015.07.034

Kemp, A.C., Horton, B.P., Culver, S.J., Corbett, D.R., van de Plassche, O., Gehrels, W.R., Douglas, B.C., Parnell, A. C., 2009. Timing and magnitude of recent accelerated sea-level rise (North Carolina, United States). Geology 37, 1035-1038. doi:10.1130/G30352A.1

Kemp, A.C., Horton, B.P., Donnelly, J.P., Mann, M.E., Vermeer, M., Rahmstorf, S., 2011. Climate related sea-level variations over the past two millennia -Supporting Information. Proc. Natl. Acad. Sci. U. S. A. 108, 11017-22. doi:10.1073/pnas.1015619108

Kemp, A.C., Horton, B.P., Vane, C.H., Bernhardt, C.E., Corbett, D.R., Engelhart, S.E., Anisfeld, S.C., Parnell, A.C., Cahill, N., 2013. Sea-level change during the last 2500 years in New Jersey, USA. Quat. Sci. Rev. 81, 90-104. doi:10.1016/j.quascirev.2013.09.024

Kemp, A.C., Sommerfield, C.K., Vane, C.H., Horton, B.P., Chenery, S., Anisfeld, S., Nikitina, D., 2012. Use of lead isotopes for developing chronologies in recent salt-marsh sediments. Quat. Geochronol. 12, 40-49. doi:10.1016/j.quageo.2012.05.004 
Kopp, R.E., Kemp, A.C., Bittermann, K., Horton, B.P., Donnelly, J.P., Gehrels, W.R., Hay, C.C., Mitrovica, J.X., Morrow, E.D., Rahmstorf, S., 2016. Temperature-driven global sea-level variability in the Common Era. Proc. Natl. Acad. Sci. 1-8. doi:10.1073/pnas.1517056113

Long, A.J., Barlow, N.L.M., Gehrels, W.R., Saher, M.H., Woodworth, P.L., Scaife, R.G., Brain, M.J., Cahill, N., 2014. Contrasting records of sea-level change in the eastern and western North Atlantic during the last 300 years. Earth Planet. Sci. Lett. 388, 110-122. DOI: 10.1016/j.epsl.2013.11.012

Marshall, W., 2015. Chronohorizons: indirect and unique event dating methods for sea-level reconstructions. In Shennan, I., Long, A.J., Horton, B.P., (eds.) Handbook of Sea-Level Research. John Wiley \& Sons. 373-385.

Michczynski, A., 2007. Is it possible to find a good point estimate of a calibrated radiocarbon date? Radiocarbon 49, 393-401.

Masson-Delmotte, V., M. Schulz, A. Abe-Ouchi, J. Beer, A. Ganopolski, J.F. González Rouco, E. Jansen, K. Lambeck, J. Luterbacher, T. Naish, T. Osborn, B. Otto-Bliesner, T. Quinn, R. Ramesh, M. Rojas, X. Shao and A. Timmermann, 2013. Information from Paleoclimate Archives. In: Climate Change 2013: The Physical Science Basis. Contribution of Working Group I to the Fifth Assessment Report of the Intergovernmental Panel on Climate Change [Stocker, T.F., D. Qin, G.-K. Plattner, M. Tignor, S.K. Allen, J. Boschung, A. Nauels, Y. Xia, V. Bex and P.M. Midgley (eds.)]. Cambridge University Press, Cambridge, United Kingdom and New York, NY, USA.

Miller, K.G., Kopp, R.E., Horton, B.P., Browning, J. V, Kemp, A.C., 2013. A geological perspective on sea-level rise and its impacts along the U.S. mid-Atlantic coast. Earth's Futur. 1, 3-18. doi:10.1002/2013EF000135

Nydick, K.R., Bidwell, A.B., Thomas, E., Varekamp, J.C., 1995. A sea-level rise curve from Guilford, Connecticut, USA. Mar. Geol. 124, 137-159. doi:10.1016/0025-3227(95)00037-Y

Parnell, A.C., Buck, C.E., Doan, T.K., 2011. A review of statistical chronology models for highresolution, proxy-based Holocene palaeoenvironmental reconstruction. Quat. Sci. Rev. 30, 2948-2960. doi:10.1016/j.quascirev.2011.07.024

Parnell, A.C., Gehrels, W.R., 2015. Using chronological models in late Holocene sea-level 
653 reconstructions from saltmarsh sediments. In Shennan, I., Long, A.J., Horton, B.P., (eds.)

654 Handbook of Sea-Level Research. John Wiley \& Sons. 500-513.

655

Shennan, I., 2015. Handbook of sea-level research: framing research questions. In Shennan, I., Long, 656 A.J., Horton, B.P., (eds.) Handbook of Sea-Level Research. John Wiley \& Sons. 3-25.

657 Telford, R., Heegaard, E., Birks, H., 2004. All age-depth models are wrong: but how badly? Quat. Sci. 658 Rev. 23, 1-5. doi:10.1016/j.quascirev.2003.11.003

659 van de Plassche, O., Edwards, R.J., van der Borg, K., de Jong, A.F.M., 2001. C-14 wiggle-match 660 dating in high-resolution sea-level research. Radiocarbon 43, 391-402. 
Table 1 Summary of chronological data

\begin{tabular}{|c|c|c|c|}
\hline Data Type & $\begin{array}{l}\text { Depth } \\
(\mathrm{cm})\end{array}$ & $\begin{array}{l}\text { Age } \\
(\text { yrs AD) }\end{array}$ & Comment \\
\hline Core top / surface & $1 \pm 0.5$ & $2001 \pm 1$ & Date of core retrieval \\
\hline${ }^{137} \mathrm{Cs}$ & $10 \pm 1$ & $1963 \pm 1$ & $\begin{array}{l}63 \text { samples, } 29 \text { depths with activity: AD1963 peak in } \\
\text { thermonuclear fallout correlate with peak activity in }{ }^{137} \mathrm{Cs} \text {. } \\
\text { Linear rate }=2.6 \pm 0.2 \mathrm{~mm} / \mathrm{yr}\end{array}$ \\
\hline${ }^{210} \mathrm{~Pb}$ & $1-42$ & $1998-1799$ & $\begin{array}{l}63 \text { samples, } 48 \text { depths with activity: age model constrained } \\
\text { by AD1963 marker using piecewise CRS approach } \\
\text { (Constant Rate of Supply, Appleby in Last and Smol, 2001; } \\
\text { Appleby, 2008). Linear rate } \sim 2.1 \mathrm{~mm} / \mathrm{yr}\end{array}$ \\
\hline Pollen & $61 \pm 3$ & $1650 \pm 50$ & $\begin{array}{l}\text { Ragweed (Ambrosia) rise at } 58 \mathrm{~cm} \text { (after AD1640) } \\
\text { correlated with historical timing of early European settlement } \\
\text { in the region (Brugham, 1978; Clark et al., 1986): assigned a } \\
\text { conservative } \pm 50 \text { age uncertainty term. Linear rate }=1.6- \\
1.9 \mathrm{~mm} / \mathrm{yr}\end{array}$ \\
\hline New London tide gauge & - & $1938-2006$ & $2.3 \mathrm{~mm} / \mathrm{yr}$ \\
\hline $\begin{array}{l}{ }^{14} \mathrm{C} \text { dates (PMS depths, } \\
\text { calibrated ages) }\end{array}$ & $26 \pm 3-176 \pm 3$ & $1953-431$ & 26 AMS dated samples \\
\hline${ }^{14} \mathrm{C}$ wiggle match rate & $26-176$ & $1888-511$ & $\begin{array}{l}1.1 \mathrm{~mm} / \mathrm{yr} \text { (also equivalent to rate of GIA): under-predicts } \\
\text { position of present day marsh surface by } 13.4 \mathrm{~cm}\end{array}$ \\
\hline
\end{tabular}

662 
664 Table 2 Summary of model specifications used in the simulations. See Appendix A for further details.

\begin{tabular}{l|l}
\hline Model & \multicolumn{1}{|c}{ Parameters } \\
\hline \hline Bacon & Mean accumulation rate $(\alpha)=1.0 \mathrm{~mm} / \mathrm{yr}$; Section thickness $=$ variable \\
Bchron & Automated procedure; Includes depth uncertainty of $\pm 3 \mathrm{~cm}$ for dated samples \\
Bpeat & Mean accumulation rate $(\alpha)=1.0 \mathrm{~mm} / \mathrm{yr} ;$ No. of sections $=15 ;$ Hiatus $A=0.5$ \\
Clam & Run length $=100,000$ iterations (exclude age reversals); Span $=0.3 ;$ smoothed spline \\
Oxcal & P_Sequence; $\mathrm{k}=2 ;$ General outlier model
\end{tabular}


667 Figure 1. Illustration of how palaeomarsh-surface (PMS) accumulation dominates the reconstructed relative sea-level (RSL) record. (a) Radiocarbon-dated plant macrofossils fix PMS position at particular points in time, producing an age-depth plot. (b) PMS elevation above mean sea level is reconstructed from sample foraminiferal content, producing a depth-elevation plot. (c) Age-depth modelling assigns a date to each foraminiferal sample to produce a reconstruction of PMS elevation change over time. The modelled accumulation curve influences the timing and shape of the reconstructed RSL change. (d) The resulting RSL reconstructions, which are typically presented following removal of the long-term (linear) trend, are strongly influenced by the choice of age-depth model.

Figure 2. Core site location and summary lithostratigraphy for Pattagansett River marsh, Connecticut, USA. NL = New London tide gauge.

Figure 3. (a) Linear 'wiggle match' of AMS radiocarbon dates from Pattagansett River marsh (Core

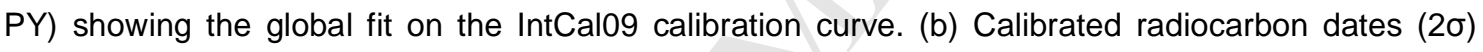
plotted alongside chronohorizons provided by an historical pollen marker (green) and the peak in ${ }^{137} \mathrm{Cs}$ (red). Forward projection of the long-term linear trend $(1.1 \mathrm{~mm} / \mathrm{yr})$ underestimates the marsh surface by $\sim 13 \mathrm{~cm}$.

Figure 4. Composite chronological dataset spanning the post-AD1600 period. (a) Ambrosia pollen abundance levels increasing above $2 \%$ indicate land clearance and provide a chronohorizon dating to AD1650 \pm 50 years. (b-e) Gamma spectrometry results including excess lead (total ${ }^{210} \mathrm{~Pb}-{ }^{226} \mathrm{Ra}$ ),

${ }^{137} \mathrm{Cs}$ and ${ }^{241} \mathrm{Am}$. The peak in atmospheric thermonuclear weapons testing and subsequent partial nuclear test ban treaty (AD1963 \pm 2 years) is correlated with the ${ }^{137} \mathrm{Cs}$ maximum and subsequent rapid fall, and the lower peak in ${ }^{241} \mathrm{Am}$. (f) The composite chronology derived from excess ${ }^{210} \mathrm{~Pb}$ results (piecewise constant rate of supply model) is shown as horizontal black bars, alongside the calibrated radiocarbon dates $(2 \sigma)$ shown as grey crosses, and the pollen (green) and ${ }^{137} \mathrm{Cs}$ (red) chronohorizons.

Figure 5. Simulated accumulation curves emulating the sampling resolution and precision of the Pattagansett River saltmarsh core for: (a) linear; and (b-c) non-linear modelling scenarios (see Table 
694 B.1 for details). Upper graphs show simulated age-depth curves (solid black lines) and synthetic

695

696

697

698

699

700

701

702

703

704

705

706

707

708

709

710

711

712

713

714

715

716

717

718

719

720

721 radiocarbon sampling points (black boxes). The 'decalibrated' radiocarbon dates derived from these points of known age are plotted as grey crosses. Additional chronohorizons are shown as green (pollen) and red $\left({ }^{137} \mathrm{Cs}\right)$ squares. Lower graphs show the simulated curves following detrending for a long-term (linear) accumulation rate of $1.1 \mathrm{~mm} / \mathrm{yr}$.

Figure 6. Graphs of best-fit $(a, c)$ and $\pm 95 \%$ confidence interval $(b, d)$ generated by the various age modelling programs for Simulation 1 (linear). Data are plotted as misfits in depth (a, b) and age (c, d) between the simulated accumulation curve and the reconstructed curves produced by the age-depth models. Line colours and envelope shading refer to the particular modelling programs indicated on the figure.

Figure 7. Graphs of best-fit (a, c, e) and $\pm 95 \%$ confidence interval $(b, d, f)$ generated by the various age modelling programs for Simulation 6 ( 21 cm oscillation). The detrended simulated (target) accumulation curve is plotted alongside the reconstructed curves produced by the age-depth models (a, b). Data are also plotted as misfits in depth (c, d) and age (e, f) between the simulated and reconstructed accumulation curves. Line colours and envelope shading refer to the particular modelling programs indicated on the figure.

Figure 8. Graphs of best-fit (a, c, e) and $\pm 95 \%$ confidence interval $(b, d, f)$ generated by the various age modelling programmes for Simulation 4 ( 13 cm oscillation). The detrended simulated (target) accumulation curve is plotted alongside the reconstructed curves produced by the age-depth models (a, b). Data are also plotted as misfits in depth (c, d) and age (e, f) between the simulated and reconstructed accumulation curves. Line colours and envelope shading refer to the particular modelling programs indicated on the figure.

Figure 9. Detrended accumulation curves for the Pattagansett River marsh core produce by: (a) Bpeat best-fit; (b) Bchron best-fit with Bchron and Oxcal confidence intervals; (c) Clam best-fit. Symbols indicate location and type of age data used in age-depth modelling. Line colours and envelope shading refer to the particular modelling programs indicated on the figure.

Figure 10. A comparison of detrended accumulation curves for the Pattagansett River marsh core illustrating the influence of dataset composition on age-depth modelling. Reconstructions are the best- 
722 fit curves (Bpeat, Bchron, Clam) and confidence intervals (Bchron, Oxcal) developed: (a) from all

723 chronological data; (b) following exclusion of the ${ }^{210} \mathrm{~Pb}$ chronohorizon; (c) following exclusion of the

724 both ${ }^{210} \mathrm{~Pb}$ and pollen chronohorizons; (d) following exclusion of both chronohorizons and possible ${ }^{14} \mathrm{C}$

725 outlier. An informal 'consensus' accumulation curve based on the complete dataset is shown in (e).

726 See text for discussion.

727 Figure 11. An illustration of the influence that radiocarbon-date precision has on the capacity of age728 depth modelling programs to accurately resolve non-linear accumulation based on Simulation $4(\sim 13$

$729 \mathrm{~cm}$ oscillation). Reconstructions are developed from synthetic data with a precision of $\pm 10{ }^{14} \mathrm{C} \mathrm{yr}(\mathrm{a}$, $730 \mathrm{~d}), \pm 35{ }^{14} \mathrm{C}$ yr (b, e) and $\pm 70{ }^{14} \mathrm{C}$ yr (c, f). Graphs of best-fit (a, b, b) and $\pm 95 \%$ confidence interval (d, 731 e, f) generated by the various modelling programmes are plotted alongside the simulated (target) 732 accumulation curve. 
734 Appendix A: Supplementary information summarising age-depth modelling packages, model scenarios and model run outputs 
(a)

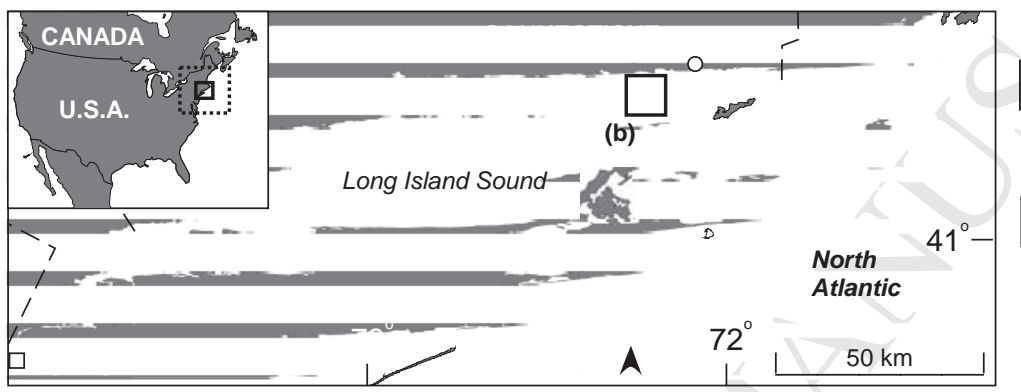

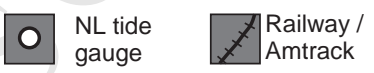

upland

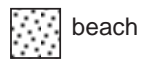

granitic outcrop

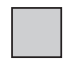

salt marsh

site

(b)

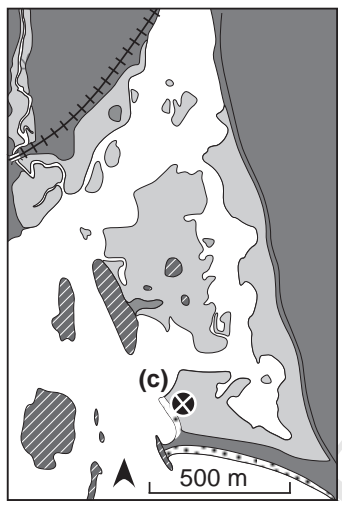

chenier

(c) 1.2 dune

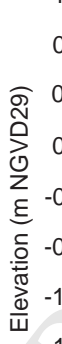

0.8

.4

$0.0 \frac{\text { sand }}{++}+$

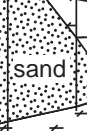

$+4+4$

$+\psi_{4}+$

$-1.2$

$-1.6$

Substrate

$-2.0$

0

5

10

15

Distance (m)

core site

East

High marsh vegetation

-S. patens

-S. alterniflora (stunted)

-S. patens (brown)

-S. patens, D. spicata (dark brown)

-D. spicata

(clayey, black/brown) 


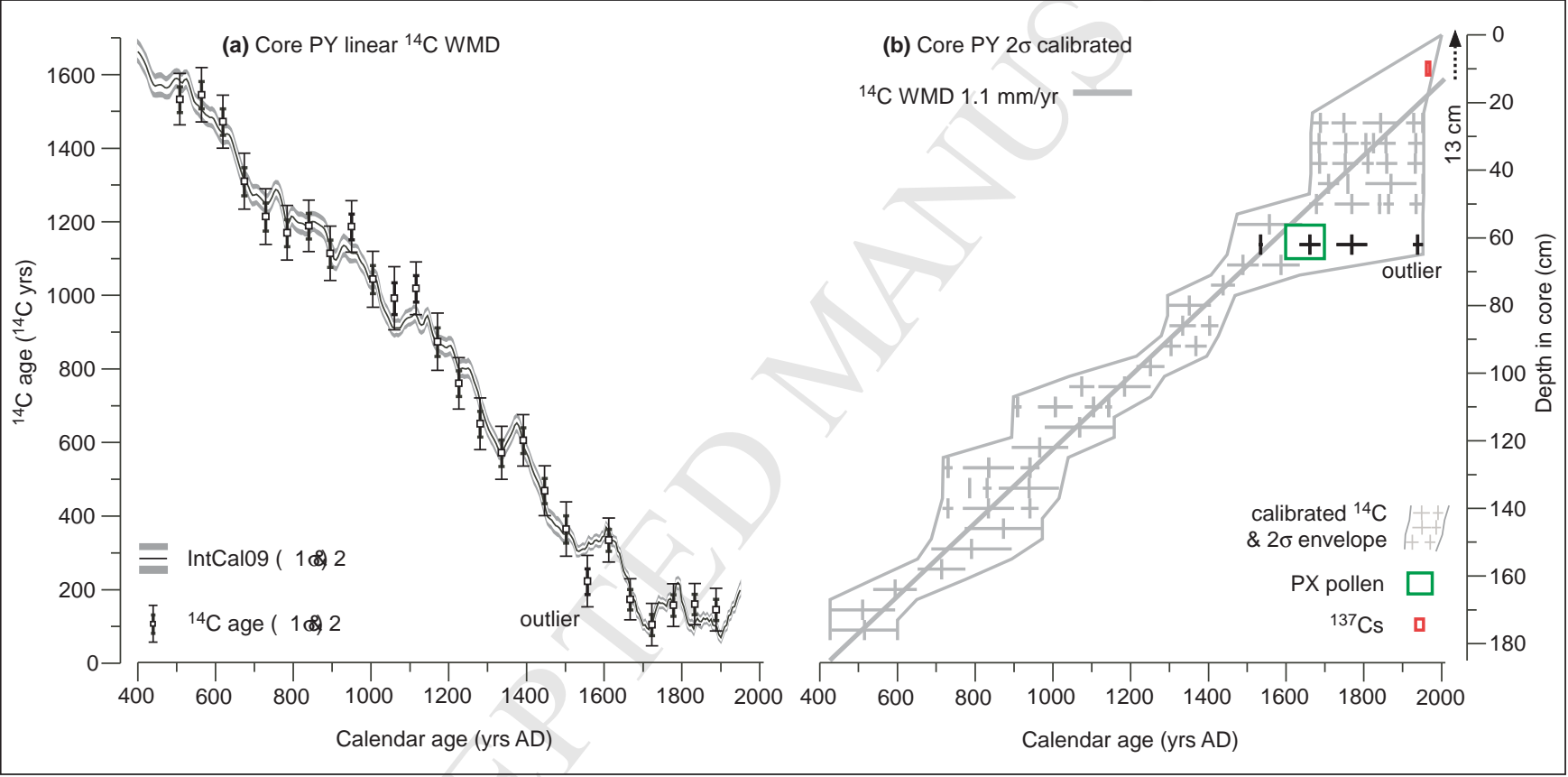



(a) Ambrosia (\%)
(b) excess ${ }^{210} \mathrm{~Pb}(\mathrm{~Bq} / \mathrm{Kg})$

(c) $L N$ excess ${ }^{210} \mathrm{~Pb}(\mathrm{~Bq} / \mathrm{Kg})$

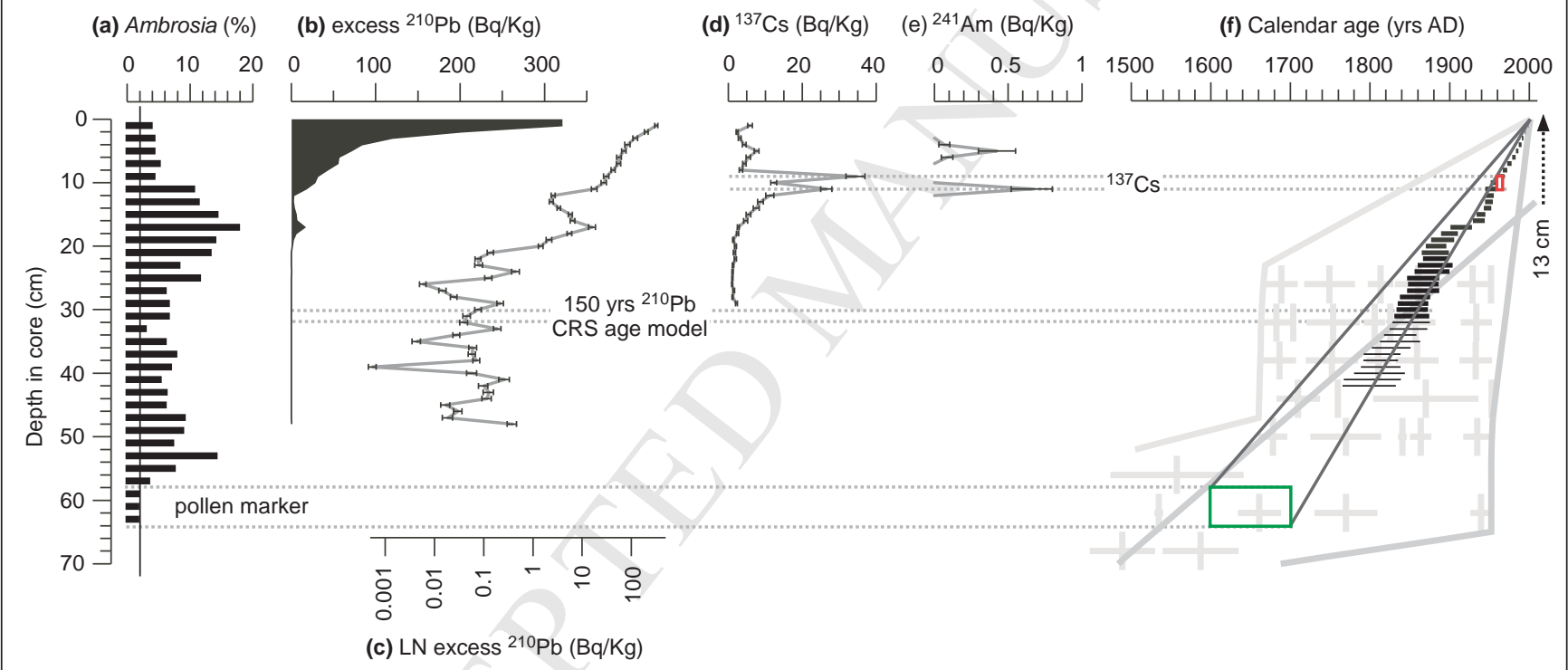
(d) ${ }^{137} \mathrm{Cs}(\mathrm{Bq} / \mathrm{Kg})$
(e) ${ }^{241} \mathrm{Am}(\mathrm{Bq} / \mathrm{Kg})$

(f) Calendar age (yrs AD)

$\begin{array}{llllllllllll}0 & 20 & 40 & 0 & 0.5 & 1 & 1500 & 1600 & 1700 & 1800 & 1900 & 2000\end{array}$

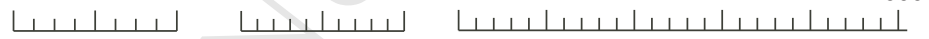

है
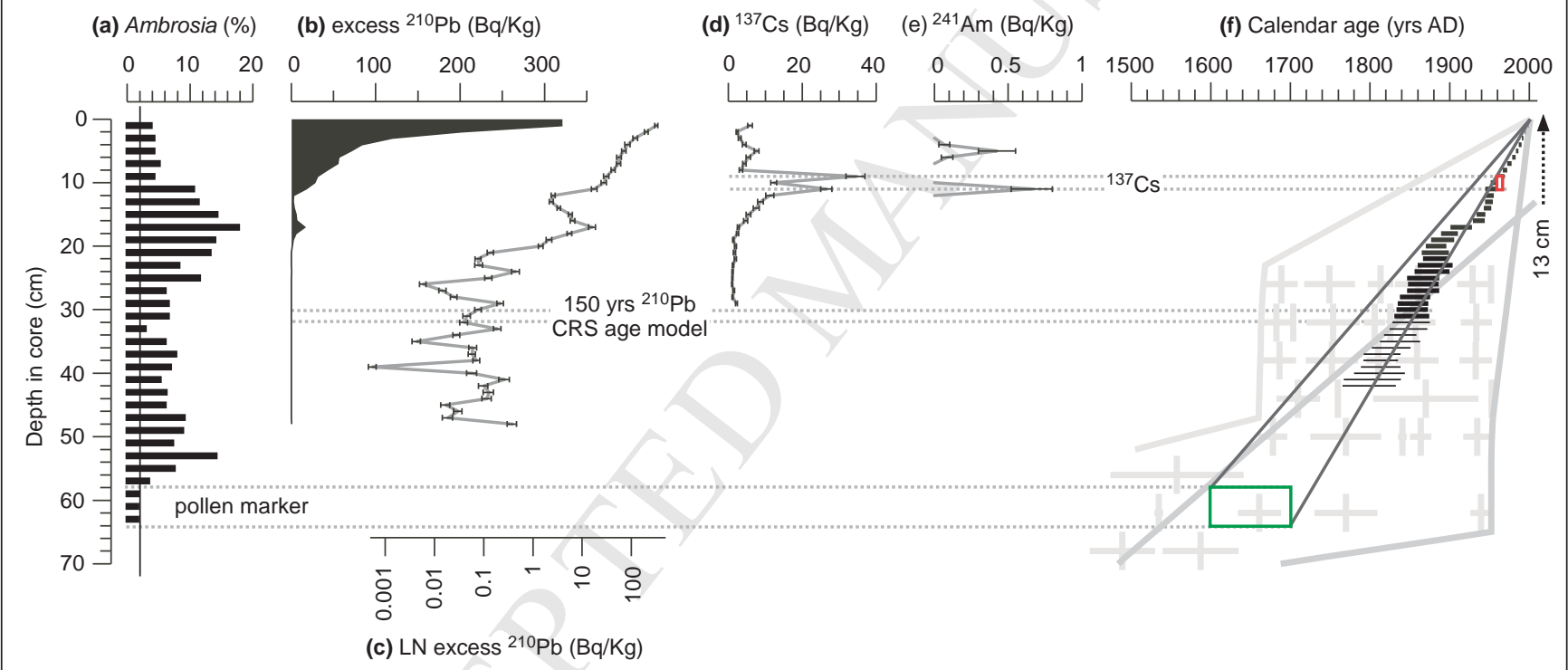


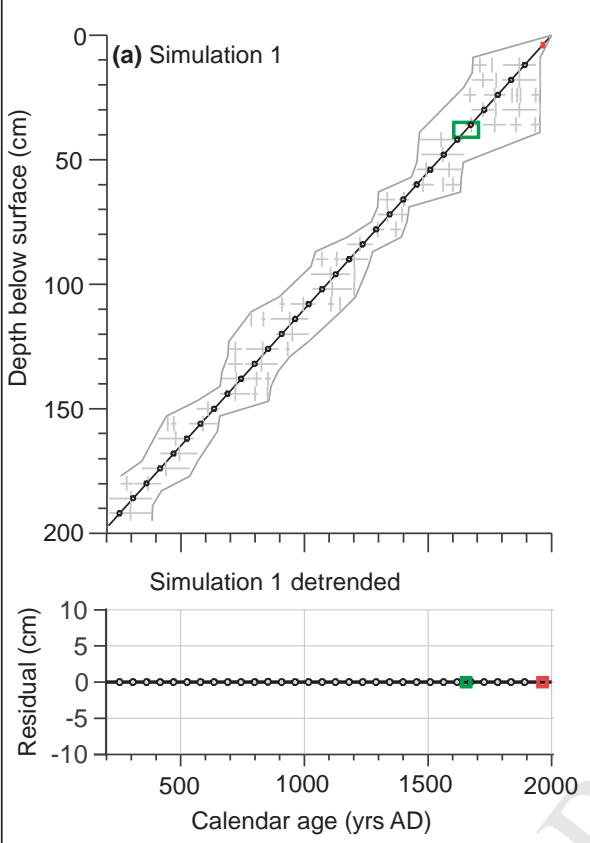

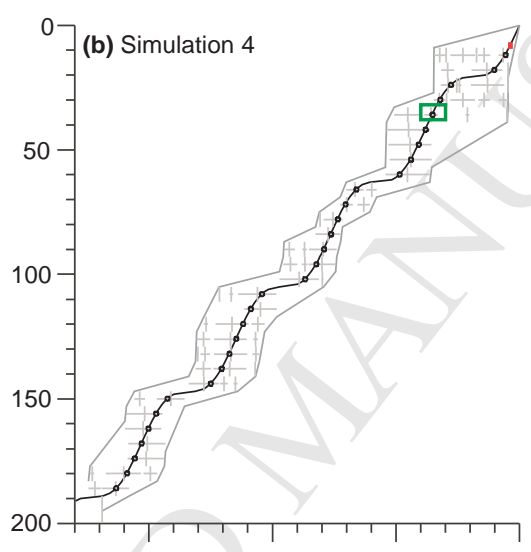

Simulation 4 detrended

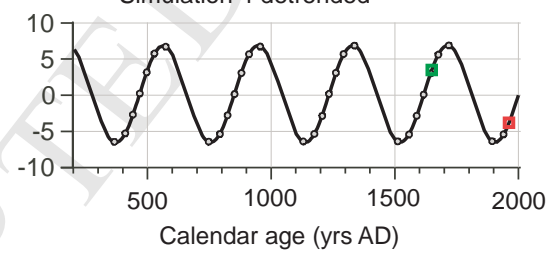

(c) Simulation 6
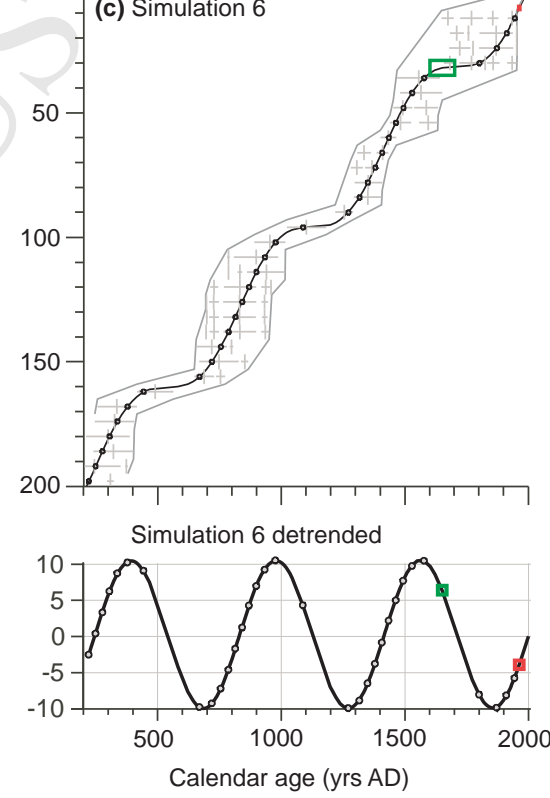

simulated age \& accumulation $\quad \square$ calibrated ${ }^{14} \mathrm{C} \& 2 \sigma$ envelope $\quad \square$ pollen $\quad$ a ${ }^{137} \mathrm{Cs}$ 
Simulation 1 - detrended curves \& depth misfit

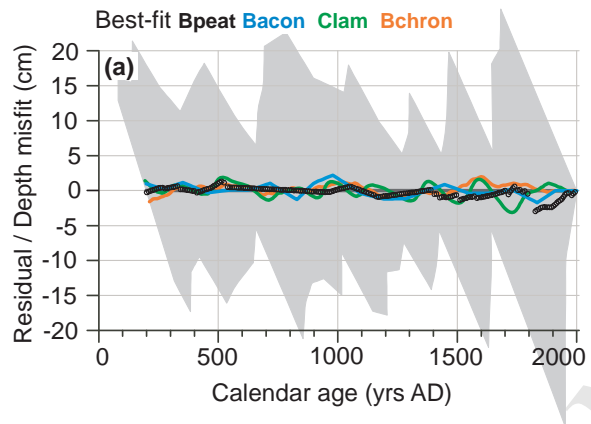

Simulated accumulation
$2 \sigma$ envelope

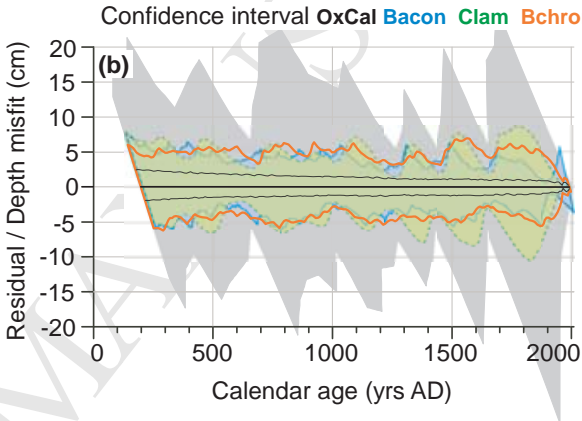

Simulation 1 - age misfit (model reconstructed age - known simulated age)

Best-fit Bpeat Bacon Clam Bchron

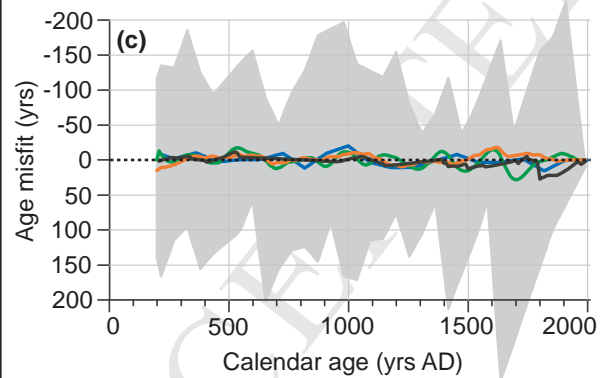

Confidence interval OxCal Bacon Clam Bchron

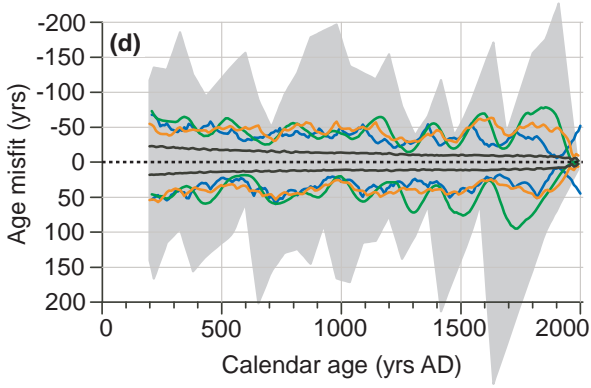



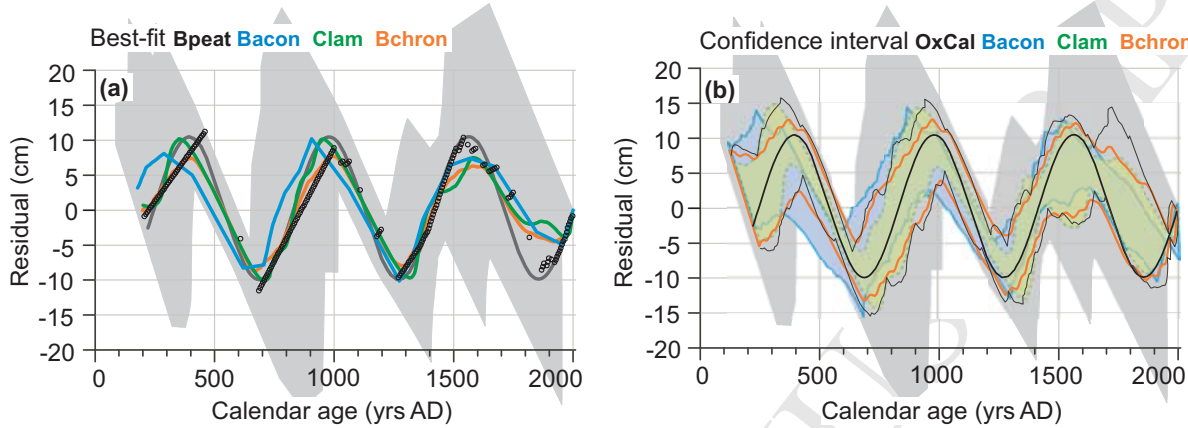

Simulation 6 - depth misfit (model reconstructed depth - known simulated depth)
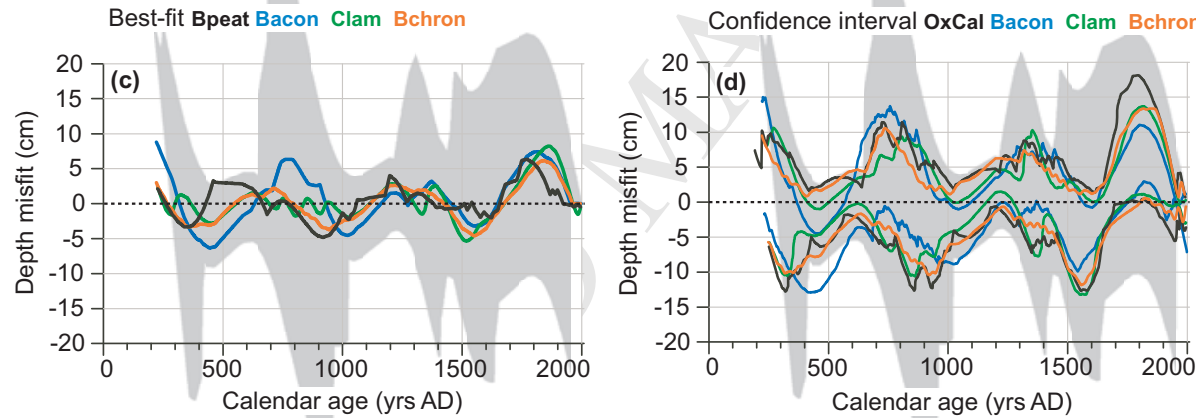

Simulation 6 - age misfit (model reconstructed age - known simulated age)

Best-fit Bpeat Bacon Clam Bchron

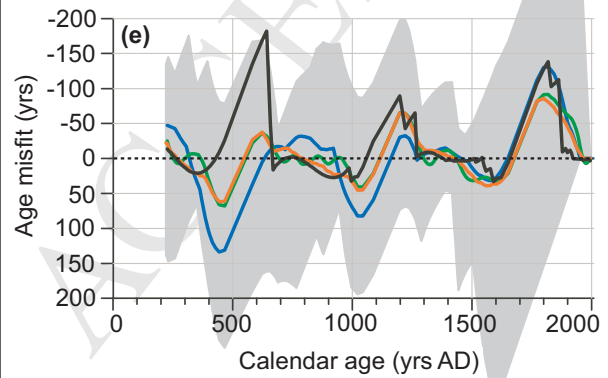

Confidence interval OxCal Bacon Clam Bchron

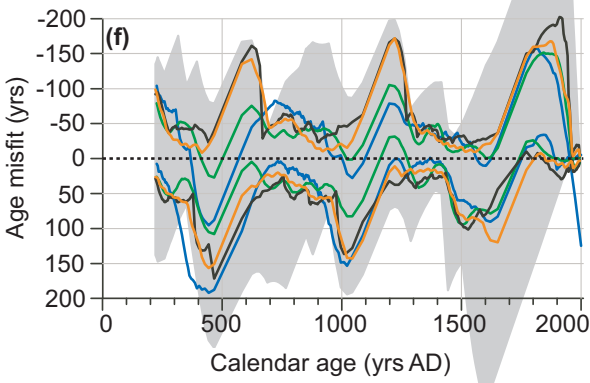


(a) best fit Bpeat ${ }_{0^{\circ}}$ 14C WMID

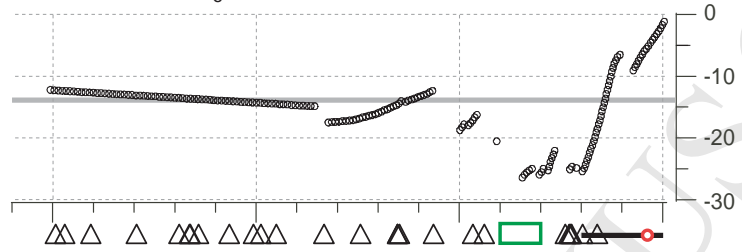

(b) best fit Bchron

confidence intervals Bchron \& OxCal

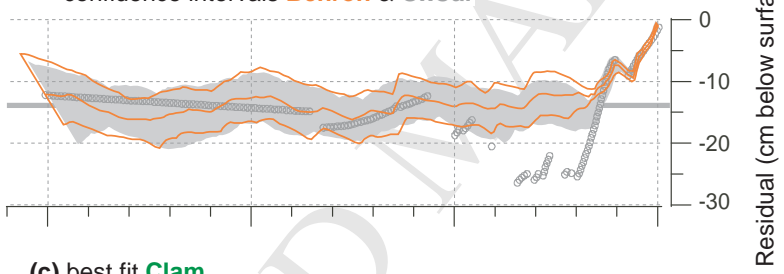

(c) best fit Clam

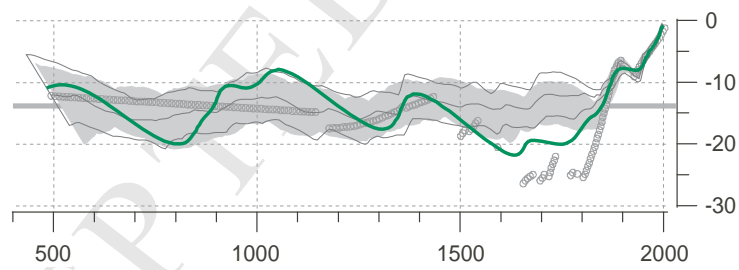

Calendar age (yrs AD)

$\triangle 14 \mathrm{C} \square$ Pollen $-210 \mathrm{~Pb} \quad 0137 \mathrm{Cs}$

WMD Bpeat Bchron OxCal $\int$ Clam 
Simulation 4 - detrended curves - Best-fit Bpeat Bacon Clam Bchron
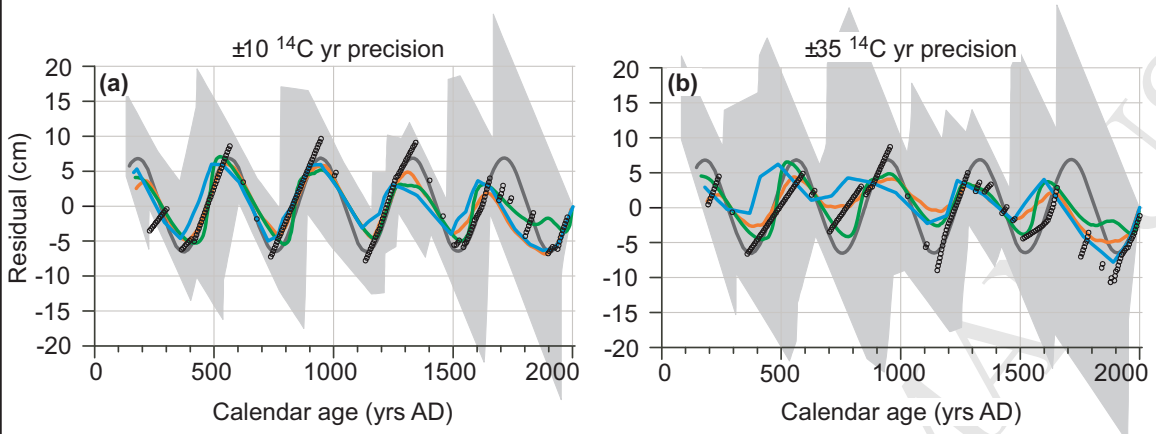

Simulation 4 - detrended curves - Confidence interval OxCal Bacon Clam Bchron
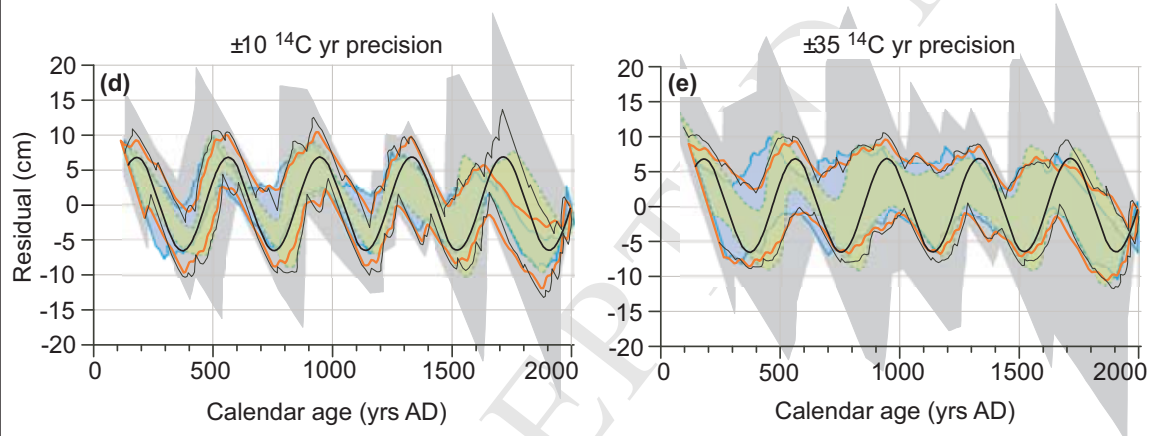
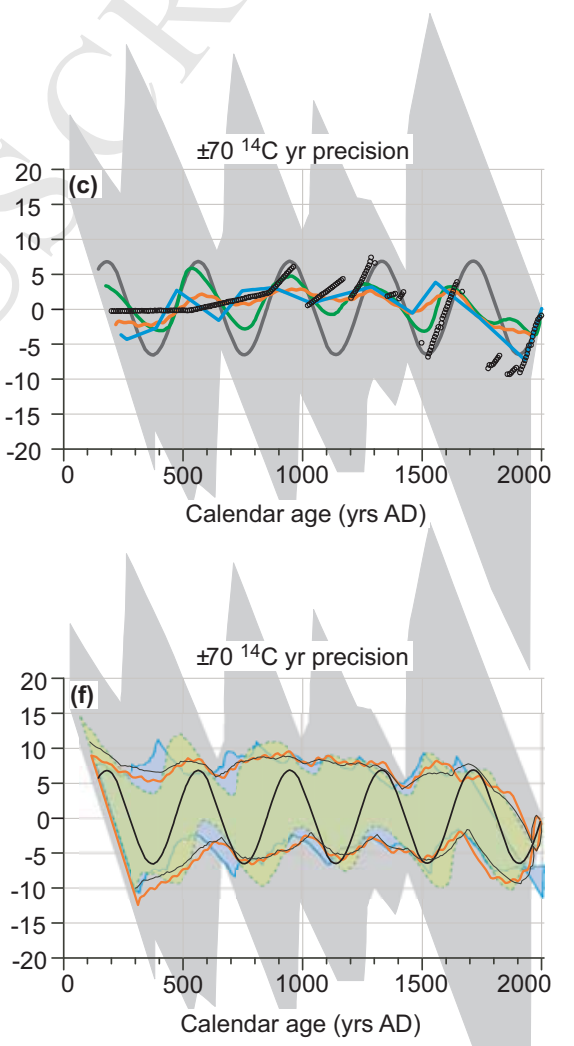


\section{Figure A1}
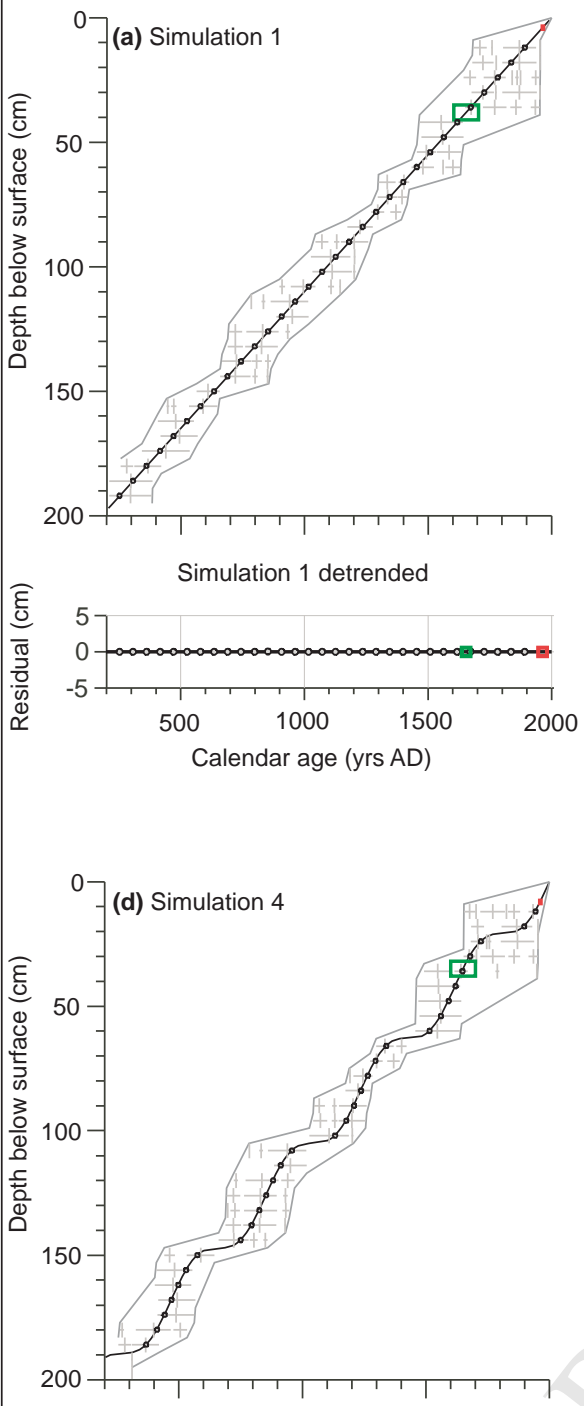

Simulation 4 detrended

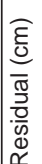

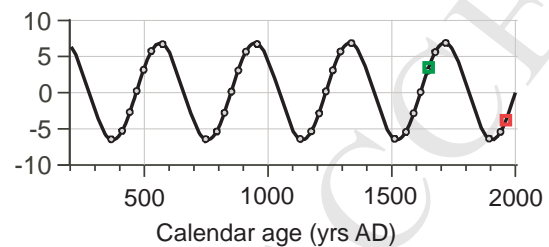

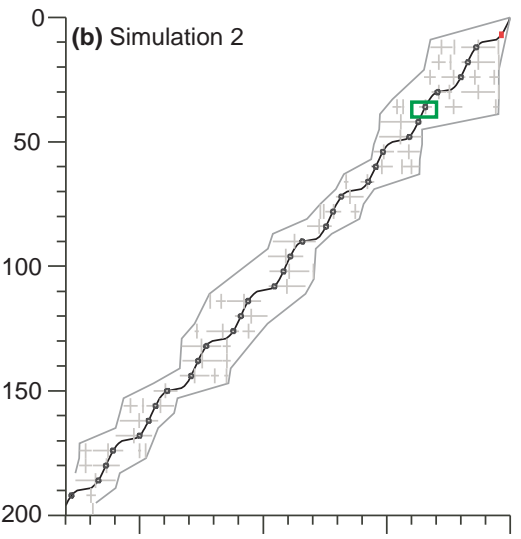

Simulation 2 detrended
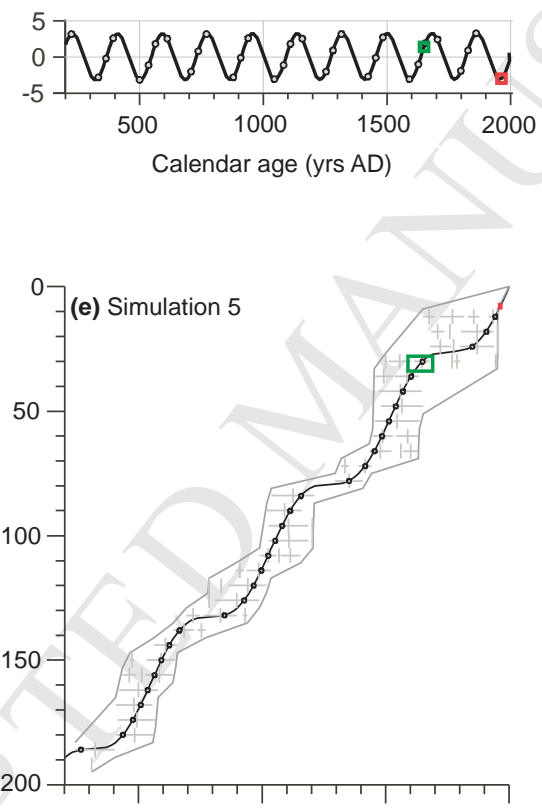

Simulation 5 detrended

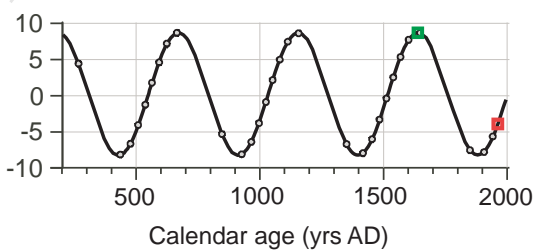

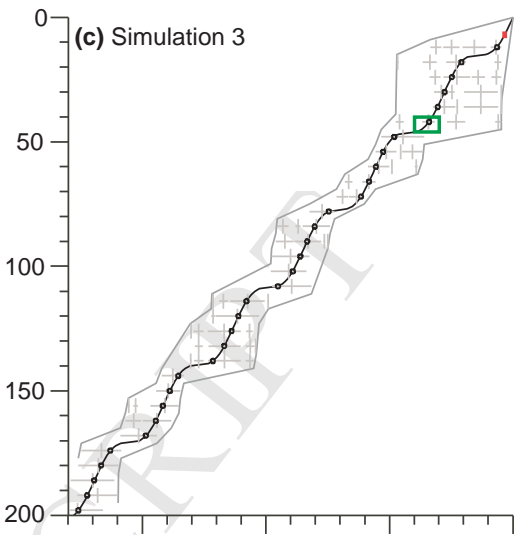

Simulation 3 detrended
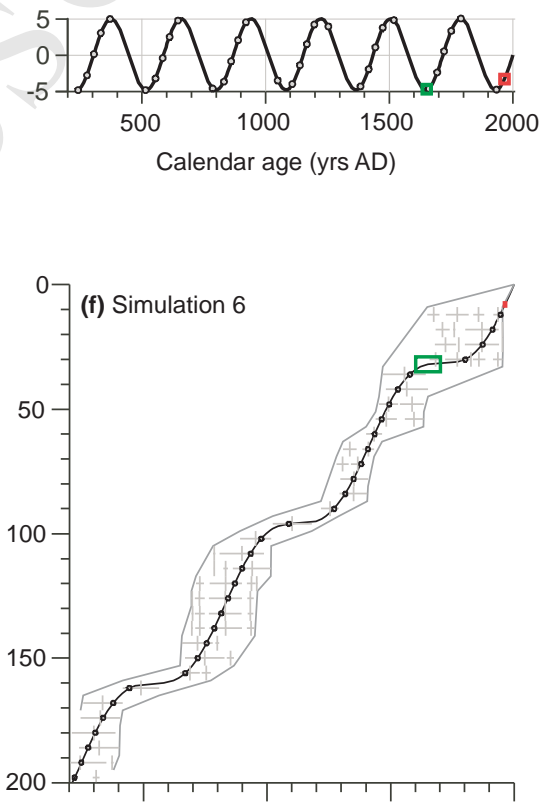

Simulation 6 detrended

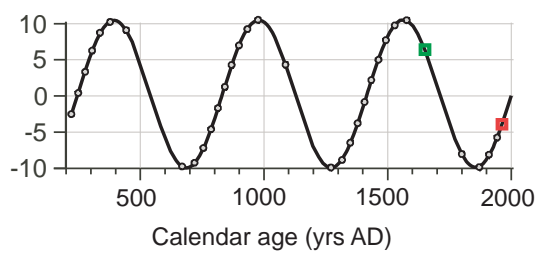

\section{1}

simulated age \& accumulation $\quad\left(\frac{++}{++}\right)$ calibrated ${ }^{14} \mathrm{C} \& 2 \sigma$ envelope $\quad \square$ pollen $\quad$ a ${ }^{137} \mathrm{Cs}$

(a-f) $2 \sigma$ calibrated and detrended 14C palaeomarsh surface accumulation simulations 1 to 6 and associated calibrated 14C age-depth envelope limited to the period 200-2000 yrs AD in this illustration for (a) linear and (b-f) nonlinear sinusoid variability tailored to cores PX and PY: GIA subsidence (0.11 cm/yr), down-core sampling $(6 \mathrm{~cm})$, age markers (pollen, $137 \mathrm{Cs}$, surface), $-35{ }^{14} \mathrm{C}$ yrs $(1 \sigma)$ average $14 \mathrm{C}$ measurement precision. Magnitude of trough-to-peak variability is close to the maximum allowed by the available accommodation space which is a combination of GIA subsidence (0.11 cm/yr) and peak-to-peak time interval for each simulation. (d) Simulation 4 nonlinear acceleration is equivalent to cores PXY modern acceleration 
(a) Simulation 1

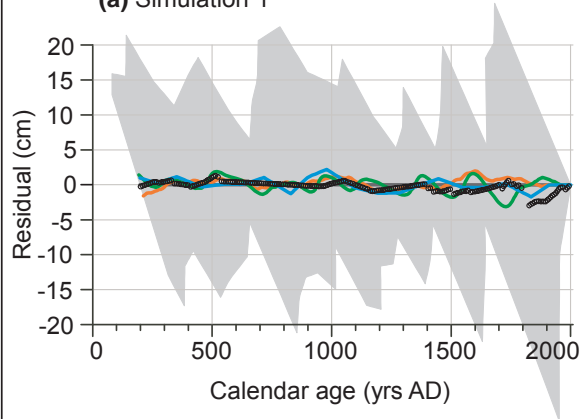

Calendar age (yrs AD) (b) Simulation 2

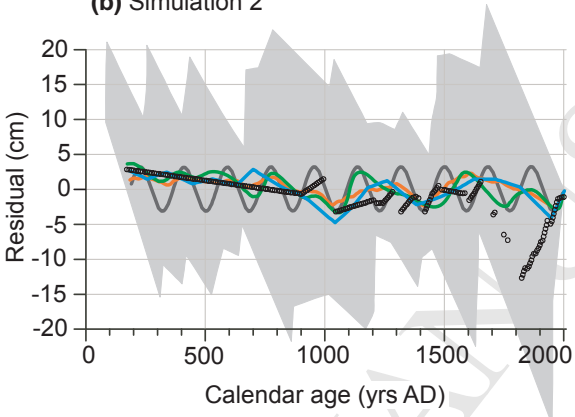

(c) Simulation 3

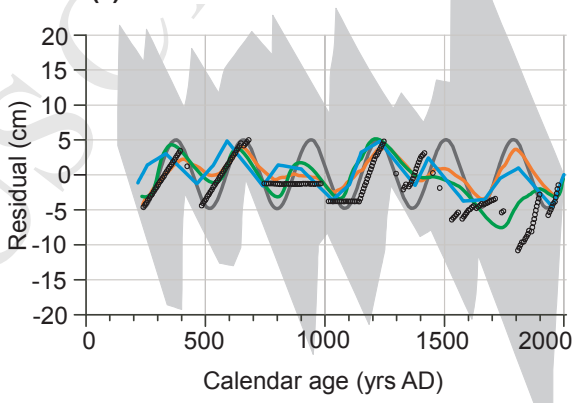

(d) Simulation 4

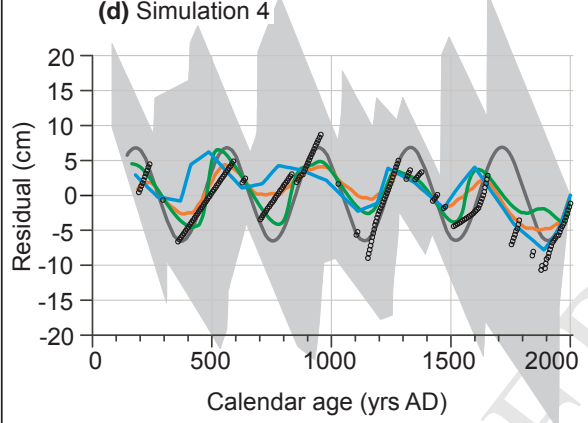

(e) Simulation 5

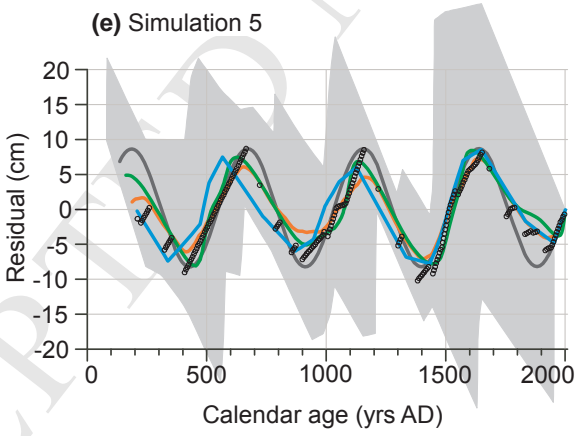

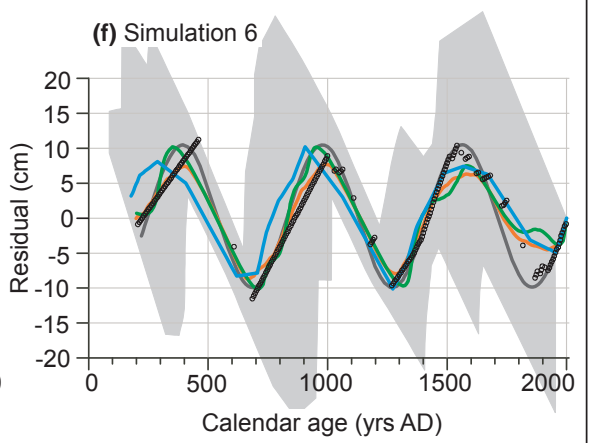

(a-f) Detrended curves $\left(-35{ }^{14} \mathrm{C}\right.$ yr precision) best fit model results grouped to compare the influence of calibration/model related artifacts (a Simulation 1) and success at predicting nonlinear palaeomarsh surface (PMS) accumulation (b-f Simulation 2 to 6). Black line represents known accumulation; age-depth envelope (grey shade, Y-axis not scaled to fit these due to excessive space requirements) encompasses individually calibrated 14C, Bpeat (black circles, mean of 3 runs using 15 sections), Bacon (blue line, mean of 3 runs), Clam (green line, 100,000 iterations using spline width 0.3), Bchron (orange line, mean of 3 standard runs). Bpeat results are represented by individual maximum a posteriori (MAP), Bacon the average MAP with step size $10 \mathrm{~cm}$ for $14 \mathrm{C}$ precision 35 yrs $(-1 \sigma)$, Clam smoothing spline individual run weighted-mean, Bchron mean average of the mode $(50 \%)$. 
(a) Simulation 1

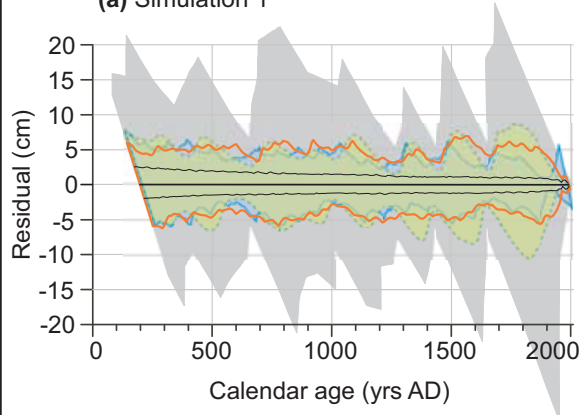

Calendar age (yrs AD) (b) Simulation 2

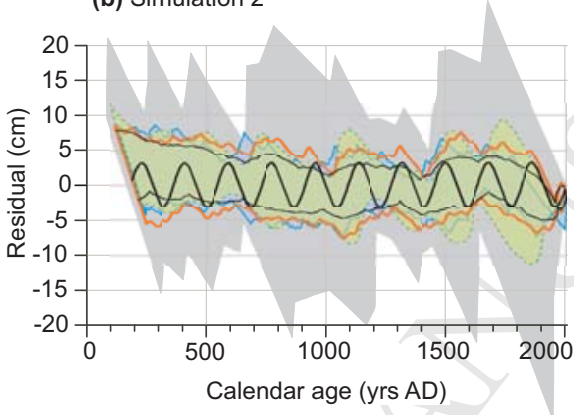

(c) Simulation 3

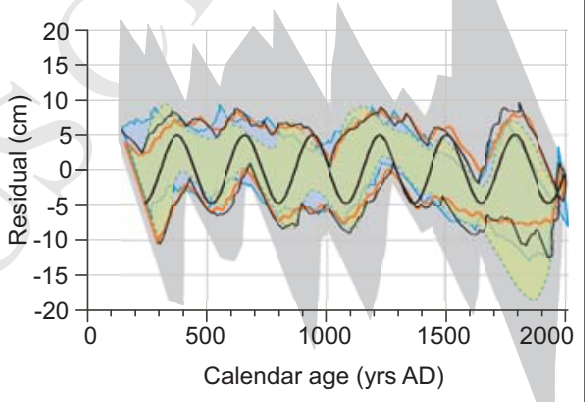

(d) Simulation 4

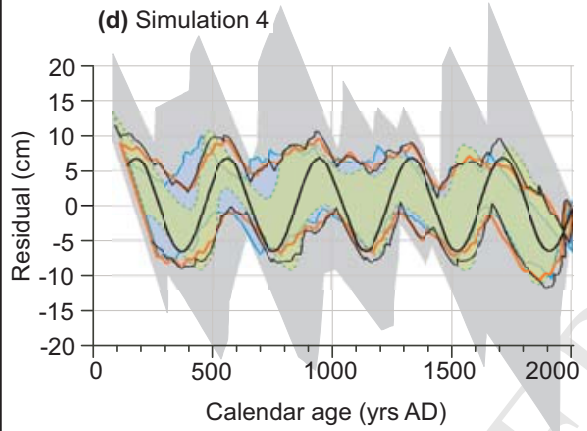

(e) Simulation 5

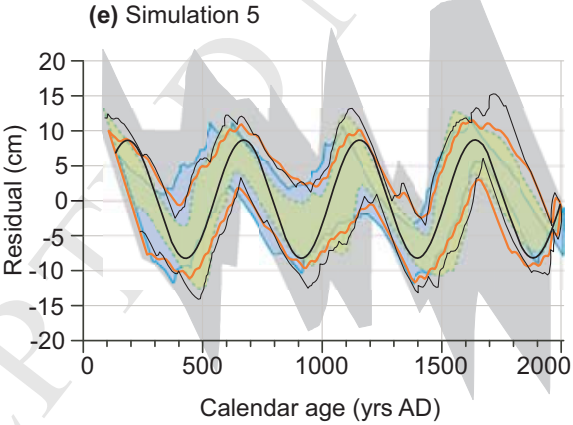

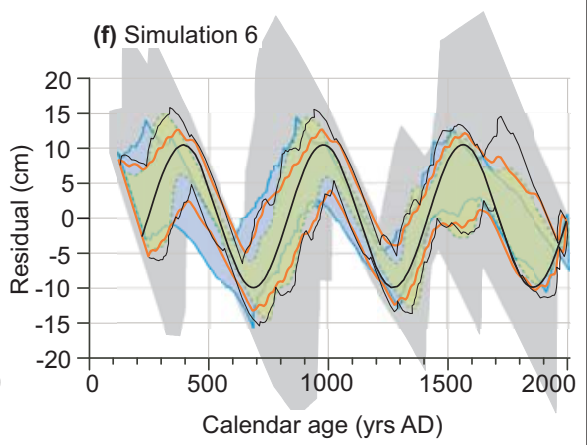

(a-f) Detrended curves $\left( \pm 35{ }^{14} \mathrm{C}\right.$ yr precision) $95 \%$ confidence interval $(\mathrm{Cl})$ model results grouped to compare model success at constraining linear (a Simulation 1) and nonlinear (b-f Simulation 2 to 6) palaeomarsh surface (PMS) accumulation. Black line represents known accumulation; age-depth envelope (grey shade, Y-axis not scaled to fit these due to excessive space requirements) encompasses individually calibrated 14C only, Bacon (blue envelope, mean of 3 runs), Clam (green envelope, 100,000 iterations using spline width 0.3), Bchron (orange lines, mean of 3 standard runs), OxCal (thin black lines, mean of 3 runs, P_Sequence $\mathrm{K}=2$ auto, General outlier model. Bacon results are represented by the $95 \%$ probability intervals (PI) with step size $10 \mathrm{~cm}$ for $14 \mathrm{C}$ precision of 35 yrs $( \pm 1 \sigma)$, Clam by the $95 \%$ confidence intervals $(\mathrm{Cl})$, Bchron by the $95 \%$ highest posterior density region (HDR defined between $2.5 \%$ and $97.5 \%$ ), OxCal by the $95 \%$ highest probability density range (HPD defined between from and to $95.4 \%$ ). 


\section{Figure A5}

Age misfit (model reconstructed age - known simulated age) - Confidence interval OxCal Bacon Clam Bchron

(a) Simulation 1

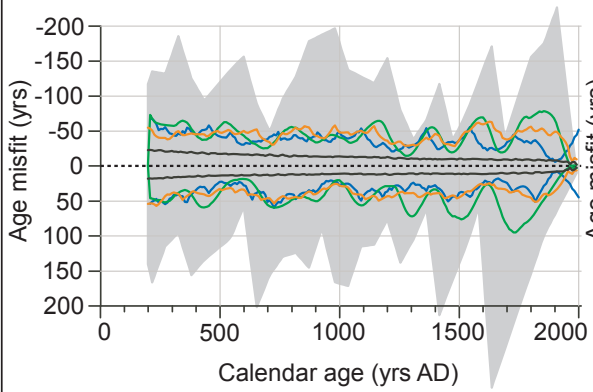

(d) Simulation 4

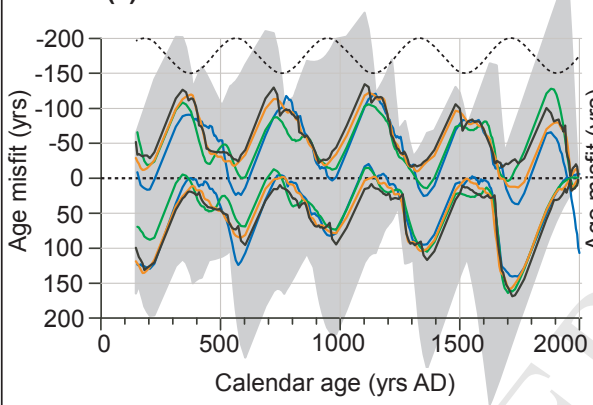

(b) Simulation 2

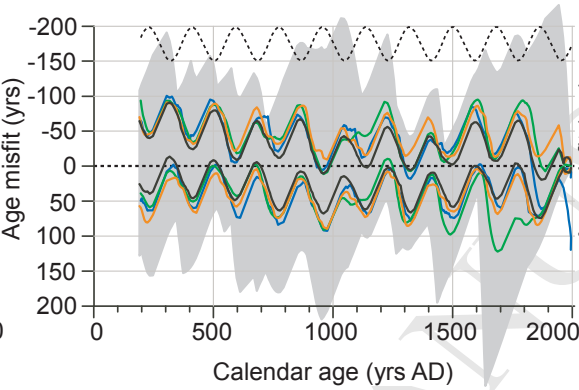

(c) Simulation 3

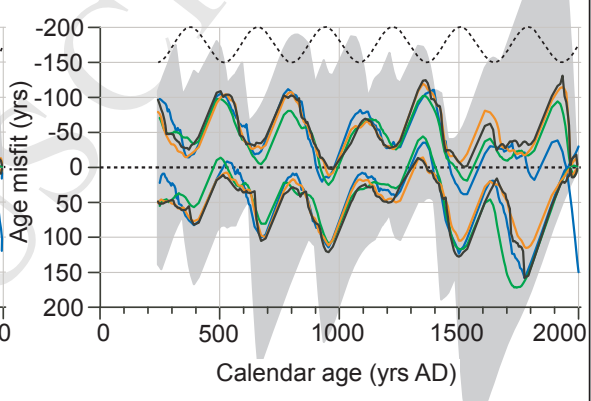

(a-f) Age misfit (model reconstructed age - known simulated age, $-35{ }^{14} \mathrm{C}$ yr precision) $-95 \%$ confidence interval $(\mathrm{Cl})$ model results grouped to compare model success at constraining linear (a Simulation 1) and nonlinear (b-f Simulation 2 to 6 ) palaeomarsh surface (PMS) accumulation. NOTE - when any CI envelope crosses the zero line (black dashed) it has no longer successfully constrained the simulated age-depth sequence. Black line dashed line represents known accumulation; age-depth envelope (grey shade, Y-axis not scaled to fit these due to excessive space requirements) encompasses individually calibrated $14 \mathrm{C}$ only, Bacon (blue lines, mean of 3 runs), Clam (green lines, 100,000 iterations using spline width 0.3), Bchron (orange lines, mean of 3 standard runs), OxCal (black lines, mean of 3 runs, $\mathrm{P}$ s Sequence $\mathrm{K}=2$ auto, General outlier model. Bacon results are represented by the $95 \%$ probability intervals (PI) with step size of $10 \mathrm{~cm}$ for $14 \mathrm{C}$ precision of $35 \mathrm{yrs}(-1 \sigma)$, Clam by the $95 \%$ confidence intervals $(\mathrm{Cl})$, Bchron by the $95 \%$ highest posterior density region (HDR defined between $2.5 \%$ and $97.5 \%$ ), OxCal by the $95 \%$ highest probability density range (HPD defined between from and to $95.4 \%$ ).

(e) Simulation 5

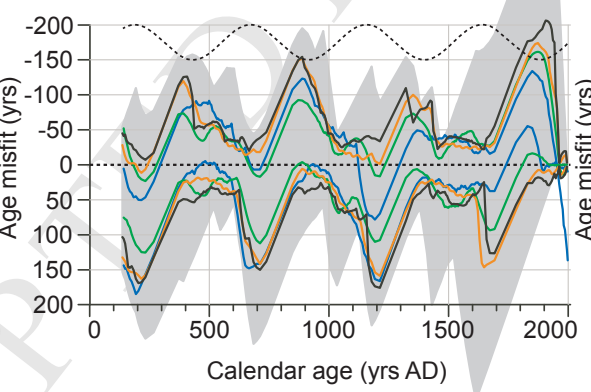

(f) Simulation 6

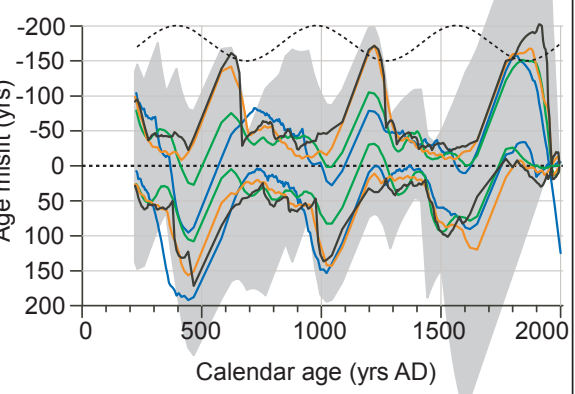




\section{Figure A8}

Depth misfit (model reconstructed depth - known simulated depth) - Confidence interval OxCal Bacon Clam Bchron

(a) Simulation 1

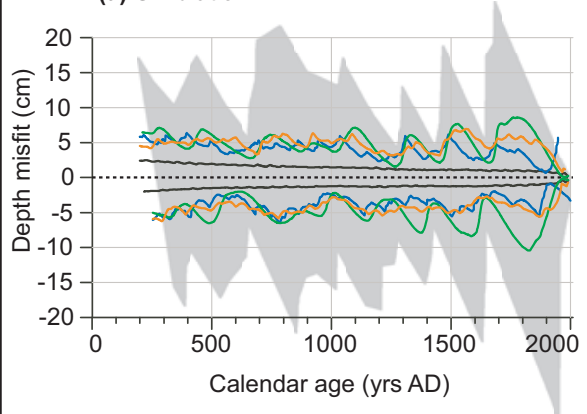

Calendar age (yrs AD) (b) Simulation 2

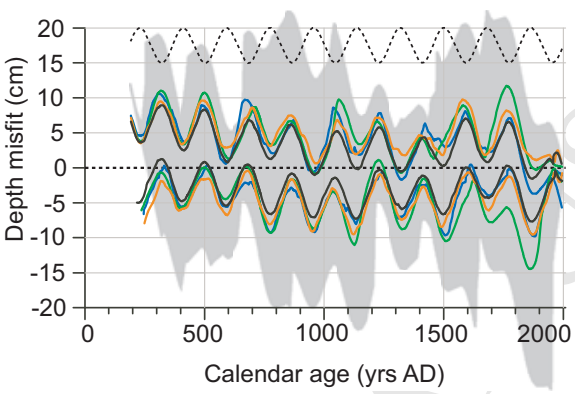

Calendar age (yrs AD)

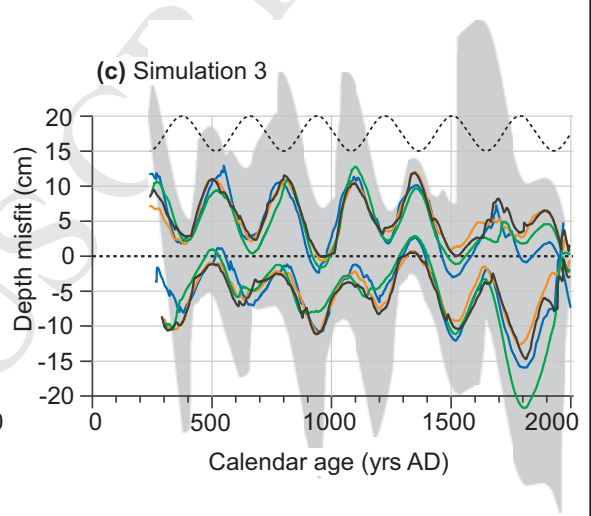

(e) Simulation 5

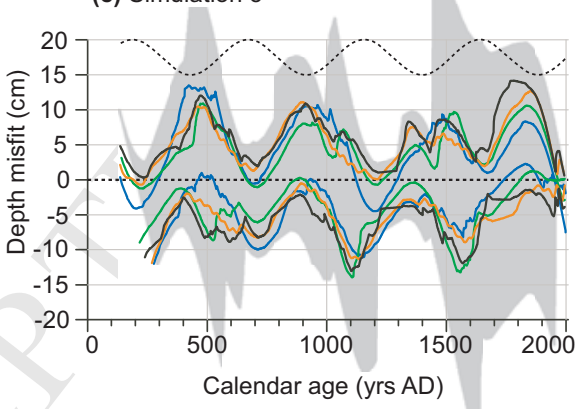

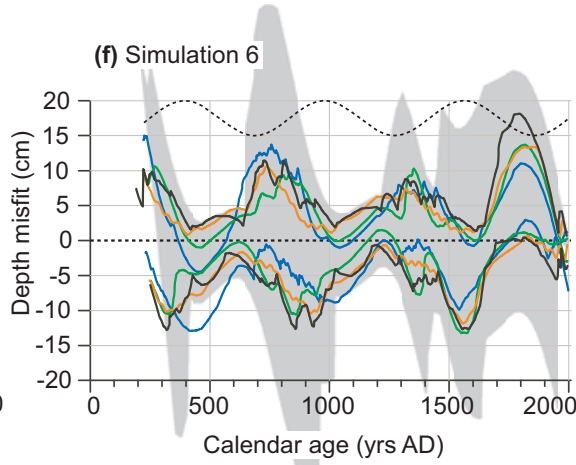

Calendar age (yrs AD)

(a-f) Depth misfit (model reconstructed depth - known simulated depth, $\pm 35{ }^{14} \mathrm{C}$ yr precision) for $\pm 95 \%$ confidence interval (Cl) model results grouped to compare model success at constraining linear (a Simulation 1) and nonlinear (b-f Simulation 2 to 6) palaeomarsh surface (PMS) accumulation. NOTE - when any $\mathrm{Cl}$ envelope crosses the zero line (black dashed) it has no longer successfully constrained the simulated age-depth sequence. Black line dashed line represents known accumulation; age-depth envelope (grey shade, Y-axis not scaled to fit these due to excessive space requirements) encompasses individually calibrated 14C only, Bacon (blue lines, mean of 3 runs), Clam (green lines, 100,000 iterations using spline width 0.3), Bchron (orange lines, mean of 3 standard runs), OxCal (black lines, mean of 3 runs, $\mathrm{P}$ _Sequence $\mathrm{K}=2$ auto, General outlier model. Bacon results are represented by the $95 \%$ probability intervals (PI) with step size of $10 \mathrm{~cm}$ for $14 \mathrm{C}$ precision of $35 \mathrm{yrs}( \pm 1 \sigma)$, Clam by the $95 \%$ confidence intervals $(\mathrm{Cl})$, Bchron by the $95 \%$ highest posterior density region (HDR defined between $2.5 \%$ and $97.5 \%$ ), OxCal by the $95 \%$ highest probability density range (HPD defined between from and to $95.4 \%$ ). 
(a) Simulation 1

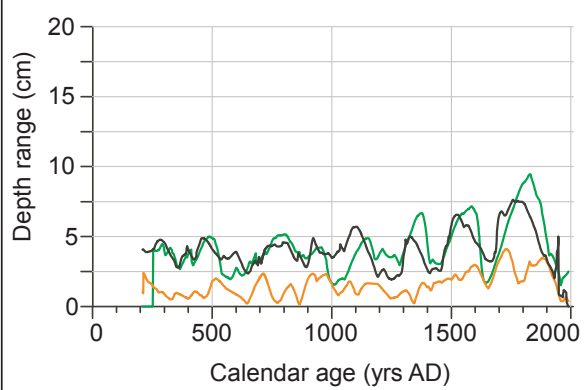

(d) Simulation 4

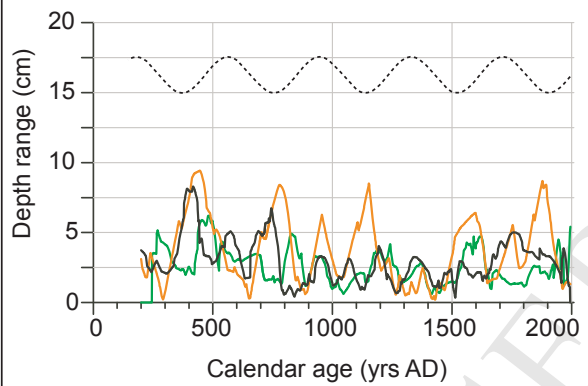

(b) Simulation 2

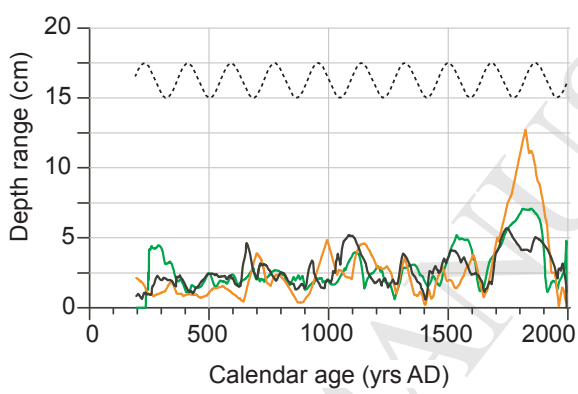

Calendar age (yrs AD) (c) Simulation 3

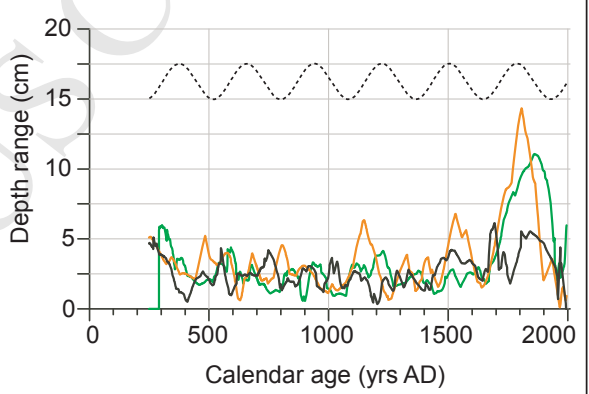

(f) Simulation 6
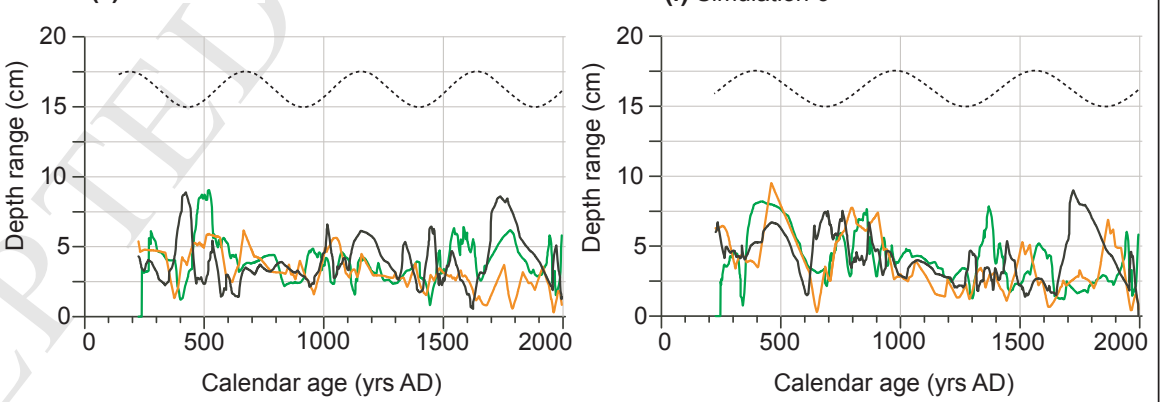

(a-f) Inter-model depth range $-35{ }^{14} \mathrm{C}$ yr precision (smallest - largest, all models to capture maximum range) for Bpeat (mean of 3 runs using 15 sections), Bacon (mean of 3 runs), Clam (100,000 iterations using spline width 0.3$)$, Bchron (mean of 3 standard runs). Bpeat results are represented by individual maximum a posteriori (MAP), Bacon the average MAP with step size $10 \mathrm{~cm}$ for $14 \mathrm{C}$ precision $35 \mathrm{yrs}(-1 \sigma)$, Clam smoothing spline individual run weightedmean, Bchron mean average of the mode (50\%). 
Detrended curves - Clam spline weighted mean $-95 \% \mathrm{Cl}_{(100,000 \text { iterations })}-0.5$ span \& 0.3 span

(a) Simulation 1

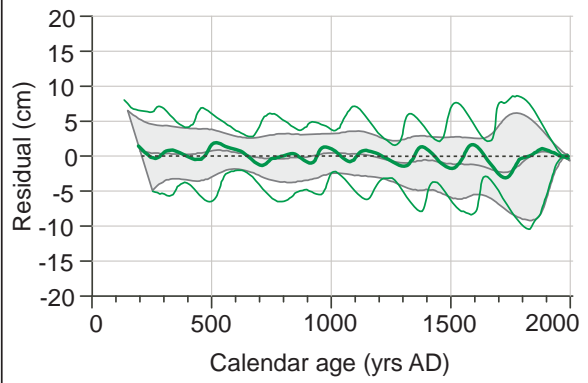

(d) Simulation 4

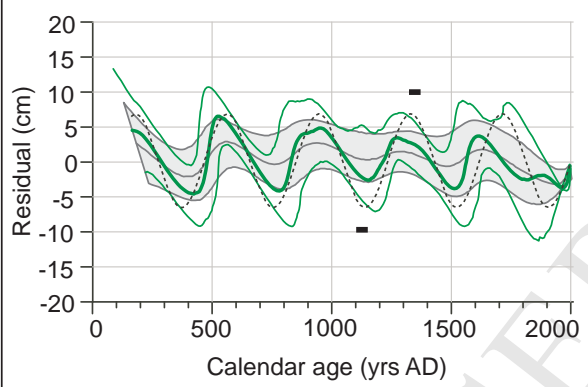

(b) Simulation 2

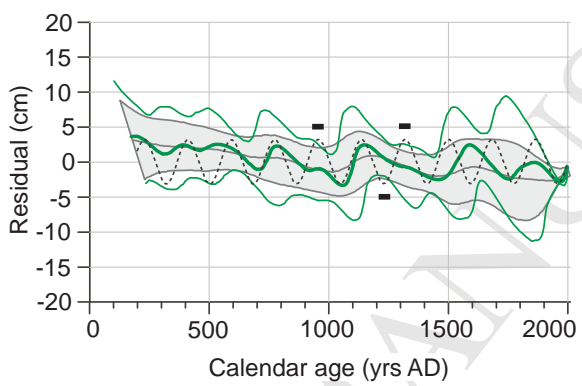

Calendar age (yrs AD) (c) Simulation 3

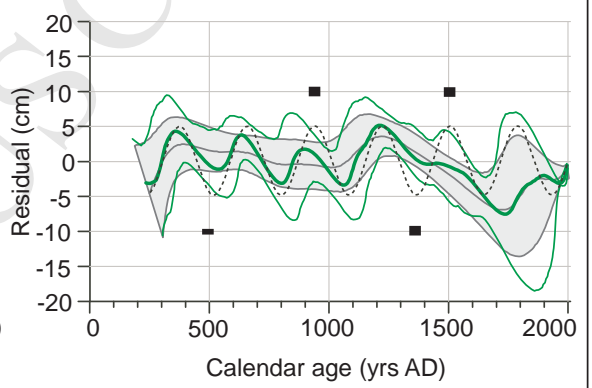

(f) Simulation 6

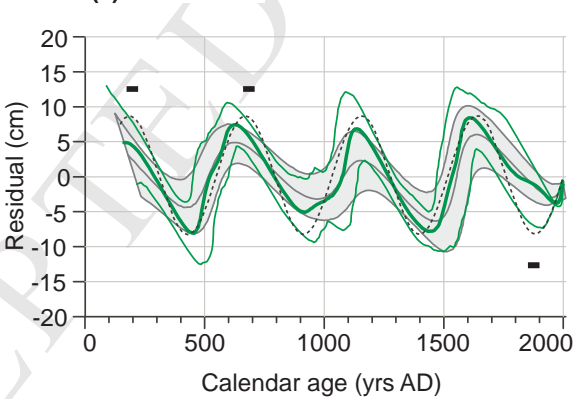

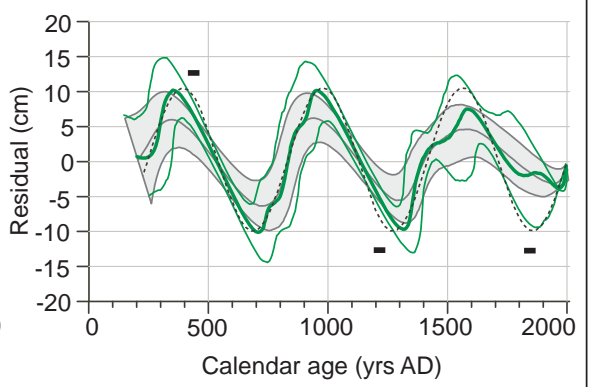

(a-f) Clam detrended curves $\left(-35{ }^{14} \mathrm{C}\right.$ yr precision) smooth spline 0.3 and 0.5 span best fit weighted mean results with $95 \%$ confidence intervals (Cl) and mean summaries, illustrate the sensitivity for incorporating calibration artefacts (linear) and allow qualitative judgement of the success with the 0.3 weighted mean has reconstructed nonlinear (sinusoidal) palaeomarsh surface accumulation and whether confidence intervals have fully contained it (black cube - clear excursion, black line - minor excursion). Span of 0.3 is clearly more sensitive than 0.5 , both vastly lower than the programme default 0.75 (not illustrated). 
(a) Simulation 1

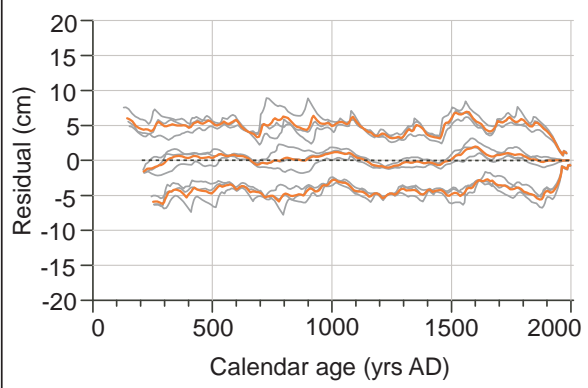

(d) Simulation 4

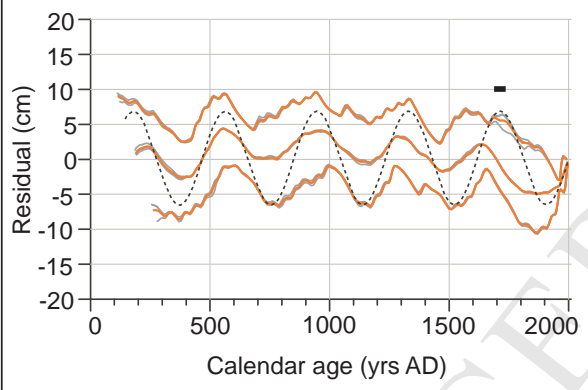

(b) Simulation 2

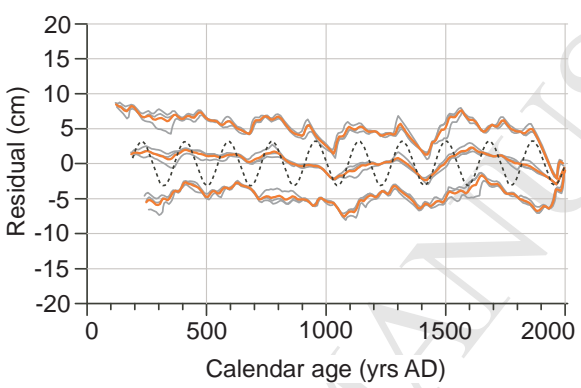

Calendar age (yrs AD) (c) Simulation 3

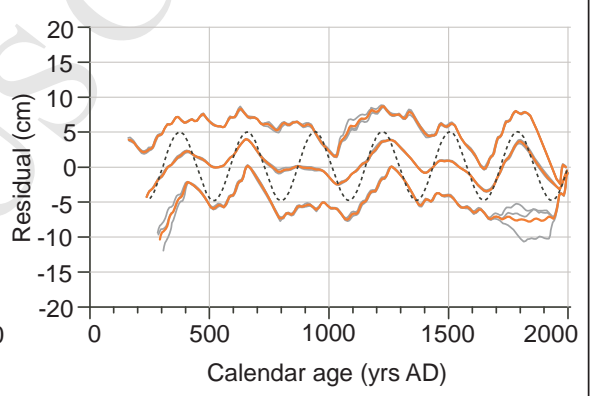

(f) Simulation 6

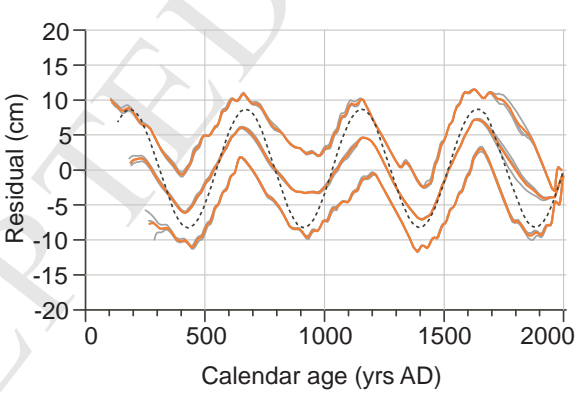

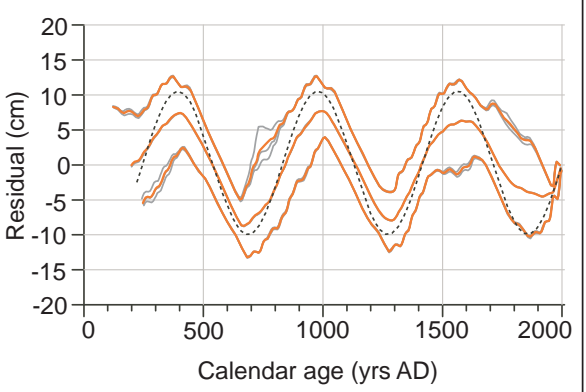

(a-f) Bchron detrended curves ( $-35{ }^{14} \mathrm{C}$ yr precision) best fit mode results with $95 \%$ highest posterior density regions (HDR) and mean summaries, illustrate the sensitivity for incorporating calibration artefacts (linear) and allow qualitative judgement of the success with the mode has reconstructed nonlinear (sinusoidal) palaeomarsh surface accumulation and whether HDR have fully contained it (black cube - clear excursion, black line - minor excursion). 
Detrended curves - OxCal $\pm 95 \% H D R$ - 3 individual runs (different outlier models)

(a) Simulation 1

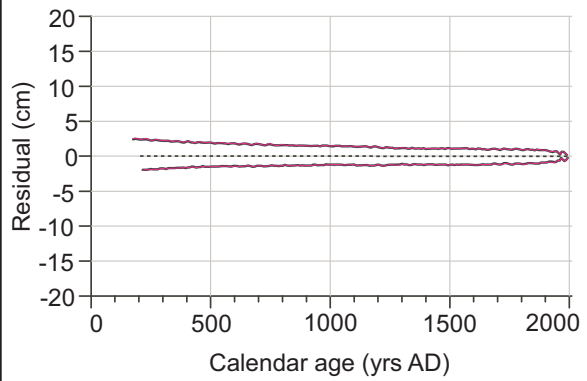

(d) Simulation 4

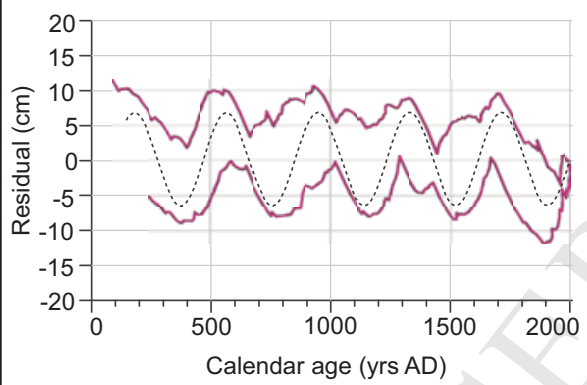

(b) Simulation 2

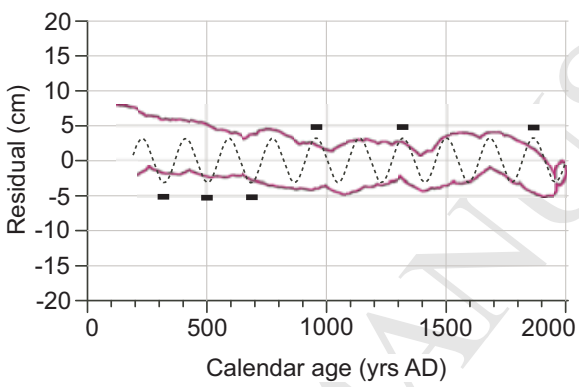

Calendar age (yrs AD) (c) Simulation 3

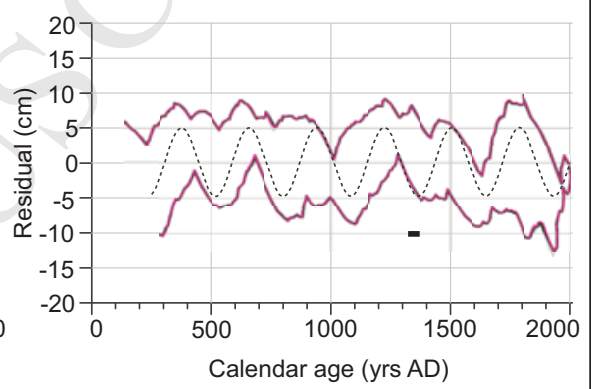

(f) Simulation 6
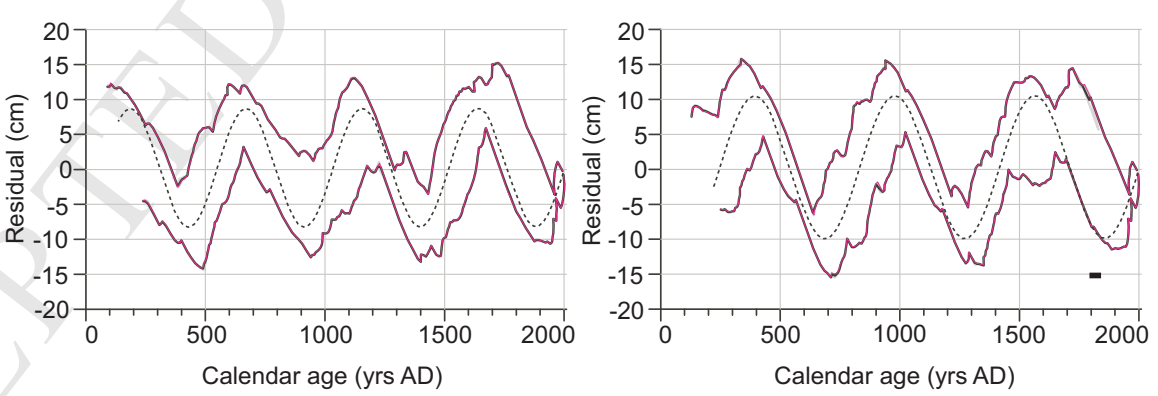

(a-f) OxCal detrended curves $\left( \pm 35^{14} \mathrm{C}\right.$ yr precision) $95 \%$ highest posterior density region (HDR defined between $2.5 \%$ and $97.5 \%$ ) using $\mathrm{P} \_$Sequence $\mathrm{K}=2$ auto, Ssimple, Rscaled \& General outlier models (grey lines), mean summary (black) and mean summary of having run with the General outlier model only (mean 3 runs), illustrate the sensitivity for incorporating calibration artefacts (linear) and allow qualitative judgement of the success with the HDR have fully contained the nonlinear (sinusoidal) palaeomarsh surface accumulation (black cube - clear excursion, black line - minor excursion). 

age-depth model is best?

Appendix A: Supplementary information summarising age-depth modelling packages, model scenarios and model run outputs

\section{Summary of model operation and setup parameters}

Age-depth modelling was performed using Bacon (Blaauw \& Christen, 2011), Bchron (Haslett \& Parnell, 2008), Bpeat (Blaauw \& Christen, 2005) and Clam (Blaauw, 2010) in the free, open-source statistical environment R (R Development Core Team, 2010). OxCal (Bronk Ramsey, 1995, 2001, 2009a) was executed via the online interface.

Bpeat

Bpeat provides numerical best-fit interpolations and grey-scale summaries. The former comprises the single iteration which best fits the model (Maximum a Posteriori - MAP), whilst the latter illustrates the full range of iterations for any given model run, but is not amenable to detrending or further analysis. We present 'best-fit' solutions based on the mean MAP results from three runs.

The user can specify the number of rate changes and the program then identifies the depth(s) at which these rate changes occur (so called change-point linear regression). The program can also detect hiatuses by accommodating age gaps between the end of one linear segment and the beginning of another. The user can adjust how the program deals with hiatuses and the extent to which accumulation rate may change between individual segments of the core, as well as setting a prior probability threshold for the identification of outliers.

Bpeat was run using a mean accumulation rate ( $\alpha$ value) of $1.0 \mathrm{~mm} / \mathrm{yr}$ (to match our simulated sequences). The number of user-defined sections was varied between 5 and 20 , with 15 proving to be optimal. Fewer sections resulted in insensitivity to non-linearities, whilst more numerous sections commonly resulting in failure to produce a coherent age-depth profile. Following preliminary analysis of a range of values $(0.005-2.0)$ a 'HiatusA' parameter of 0.5 was selected on the basis of good fit with simulated curves, and reflecting the low probability and duration of hiatuses associated with the Connecticut core.

\section{Prior parameter settings - altered within the $\mathrm{R}$ interface}


766

767

768

769

770

771

772

773

774

775

776

777

778

779

780

781

782

783

784

785

786

787

788

789

790

name=.dat file "name" within similarly named folder

nsecs=number of sections $(2) \quad(2,5,10,15)$

mindepth=minimum core depth $\mathrm{cm}$

maxdepth=maximum core depth $\mathrm{cm}$

RemoveExtremes=remove $14 \mathrm{C}$ probabilities falling outside calibration curve

(FALSE)

OUT=outlier analysis $1=y e s, 0=$ no

OUTLPPROB $=$ outlier probability 0 to 1.0

Prior parameter settings - altered within the "constants template.R" file

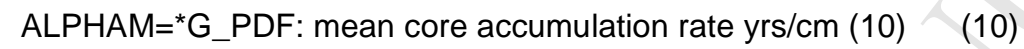

ALPHASTD $={ }^{*}$ G_PDF: standard deviation accumulation rate $\mathrm{yrs} / \mathrm{cm}(5)$

EPSILON $={ }^{*}$ G_PDF: larger values $=$ greater section dependency $(5)$

HIATUSA $={ }^{*}$ G_PDF: 'shape' higher values $=$ more 'peaked' PDF $(0.005) \quad(0.5)$

HIATUSB $={ }^{*}$ G_PDF: 'rate' duration $1 / 2=$ short, $1 / 2000=$ long $(1 / 200)$

\section{Bacon}

Bacon provides numerical best-fit and confidence interval interpolations, grey scale summaries and is superficially similar to Bpeat in terms of its tuneable parameters, with section 'thickness' operating in a similar manner to number of sections. As before, the mean accumulation rate is set at $1.0 \mathrm{~mm} / \mathrm{yr}$ and the influence of section thickness was explored in multiple runs. Whilst the selection of small section thicknesses tended to produce smoothed reconstructions, larger thicknesses had the effect of shifting accumulation rates out of phase with known variability. The precision of the radiocarbon dates also influenced the effect of section thickness with the result that different optimal values were determined 
791 for the different precisions applied here. Bacon automatically handles outliers based on student-t 792 distributions with wider tails than a normal distribution.

793 Prior parameter settings - altered within the R interface

794 core=.dat file "name" within similarly named folder

795 res=section thickness $\mathrm{cm}(5)$ [nsecs] (20 to 2.5 in steps of 2.5$)$

796 d.min=minimum core depth $\mathrm{cm}(0)$

797 d.max=maximum core depth $\mathrm{cm}(200)$

798 default.acc default accumulation rate shape (2) \& mean (10) [ALPHA]

799 acc.shape *G_PDF: higher values result in more 'peaked' distributions

(4)

800 acc.mean $\quad{ }^{*}$ G_PDF: controls the mean rate $\mathrm{yrs} / \mathrm{cm}(10)$

801

802

default.mem section dependency strength (4) \& mean (0.7) [EPSILON]

803

mem.strength *G_PDF: larger values = more 'peaked' distributions

(4)

804

mem.mean $\quad{ }^{*}$ G_PDF: controls the dependency PDF mean

805

806

default.hiatus default known/unknown hiatus shape (1) \& mean (100) [HIATUS]

807

hiatus.depths location of any known hiatus depths $\mathrm{cm}$

808

hiatus.shape *G_PDF: larger values = more 'peaked' distributions

809

hiatus.mean *G_PDF: controls the hiatus PDF mean (100)

810

811

Bchron

812

Bchron (v. 3.1.4) provides numerical best-fit and confidence interval interpolations which are

813 performed between pairs of dated levels assuming 'piecewise linear' sediment accumulation in a 814 manner referred to as 'stochastic linear interpolation' (Parnell et al., 2008 p. 1875). Whilst the program 815 proved time consuming to install and run, it has the great advantage of being fully automated and 
816 therefore does not require extensive preliminary analysis to determine optimal parameters. Bchron is

817 the only program that allows for depth ranges to be included for a given sample, thereby accounting

818 for the palaeomarsh-surface range applied to radiocarbon-dated plant macrofossils. Inclusion of this 819 depth uncertainty (i.e. $\pm 3 \mathrm{~cm}$ ) has the effect of increasing the width of confidence intervals which 820 subsequently do a better job of constraining known accumulation variability.

\section{Clam}

Clam (v. 2.0) employs classical age-depth modelling, provides both numerical best-fit and confidence interval interpolations and was developed as a quick and transparent way to produce age-depth models. It is a useful 'first-step' tool for exploring how choices made during the modelling process (e.g. interpolation method, inferred presence of hiatuses etc.) may influence the resulting chronology. Whilst less sophisticated than its Bayesian counterparts, Clam employs Monte Carlo algorithms to sample from, and thus reflect, the multi-modal probability distributions associated with calibrated radiocarbon dates. It will endeavour to fit all dated levels (i.e. there is no automatic outlier detection) and can produce models with age reversals, although there is an option to exclude these once generated. Clam will then interpolate between dated points either by applying a (global) linear solution or some form of curve (e.g. a smoothed polynomial or locally weighted spline). We used model runs employing 100,000 iterations and excluded all iterations with age-reversals. Preliminary runs using the default span (0.75) proved unsatisfactory as substantial smoothing of oscillations occurred. Further analysis revealed that a span of 0.3 coupled with a smoothed spline produced the optimal 'best-fit' solution, capturing the amplitude of simulated change whilst generating confidence intervals that circumscribed most of the known variability.

838 Oxcal (online v. 4.2) provides numerical confidence interval interpolations and includes several 839 different types of age-depth model. We used P_Sequence which is the most appropriate for the kind 840 of depositional context considered here (Bronk Ramsey, 2008). Similar to Bchron it employs an 841 incremental sedimentation model but in this instance the size of the sedimentation 'event' is a 842 tuneable parameter $(k)$ which determines how many increments are required to complete the entire 843 sequence. Varying $\mathrm{k}$ impacts rigidity of the entire age-depth model and we ran a series of model 844 evaluations ( $k$ values ranging from 0.1 to 1000 ) before employing a nominal $k$ value of 2 , whilst 
845 allowing the model to adjust this within a specified range. Oxcal has additional functionality in the 846 manner in which outliers are identified during age-depth modelling. We compared the S_simple, 847 R_scaled and General outlier models before opting for the latter. 
Table A.1 Attributes of nonlinear simulated accumulation

\begin{tabular}{|c|c|c|c|c|c|}
\hline Parameter & SIM 2 & SIM 3 & SIM 4 & SIM 5 & SIM 6 \\
\hline $\begin{array}{l}\text { Period (yrs) } \\
\text { peak-to-peak }\end{array}$ & $200 \mathrm{yrs}$ & $300 \mathrm{yrs}$ & 400 yrs & 500 yrs & $600 \mathrm{yrs}$ \\
\hline $\begin{array}{l}\text { Resolution (no.) } \\
\text { peak-to-peak samples }\end{array}$ & 3.7 & 5.5 & 7.3 & 9.2 & 11.0 \\
\hline $\begin{array}{l}\text { Linear GIA }(\mathrm{cm}) \\
\text { peak-to-peak contribution }\end{array}$ & $22.0 \mathrm{~cm}$ & $33.0 \mathrm{~cm}$ & $44.0 \mathrm{~cm}$ & $55.0 \mathrm{~cm}$ & $66.0 \mathrm{~cm}$ \\
\hline $\begin{array}{l}\text { Amplitude }( \pm \mathrm{cm}) \text { applied } \\
\& \text { [max. possible] }\end{array}$ & $\begin{array}{l} \pm 3.2 \mathrm{~cm} \\
{[ \pm 3.5 \mathrm{~cm}]}\end{array}$ & $\begin{array}{l} \pm 5.0 \mathrm{~cm} \\
{[ \pm 5.3 \mathrm{~cm}]}\end{array}$ & $\begin{array}{l} \pm 6.7 \mathrm{~cm} \\
{[ \pm 7.1 \mathrm{~cm}]}\end{array}$ & $\begin{array}{l} \pm 8.5 \mathrm{~cm} \\
{[ \pm 8.8 \mathrm{~cm}]}\end{array}$ & $\begin{array}{l} \pm 10.3 \mathrm{~cm} \\
{[ \pm 10.6 \mathrm{~cm}]}\end{array}$ \\
\hline $\begin{array}{l}\text { Total acceleration (cm yrs) } \\
\text { trough-to-peak }\end{array}$ & $\begin{array}{l}17.4 \mathrm{~cm} \text { in } \\
100 \mathrm{yrs}\end{array}$ & $\begin{array}{l}26.5 \mathrm{~cm} \text { in } \\
150 \mathrm{yrs}\end{array}$ & $\begin{array}{l}35.4 \mathrm{~cm} \text { in } \\
200 \mathrm{yrs}\end{array}$ & $\begin{array}{l}44.5 \mathrm{~cm} \text { in } \\
250 \mathrm{yrs}\end{array}$ & $\begin{array}{l}53.6 \mathrm{~cm} \text { in } \\
300 \mathrm{yrs}\end{array}$ \\
\hline $\begin{array}{l}\text { Linear GIA }(\mathrm{cm}) \\
\text { trough-to-peak contribution }\end{array}$ & $11.0 \mathrm{~cm}$ & $16.5 \mathrm{~cm}$ & $22.0 \mathrm{~cm}$ & $27.5 \mathrm{~cm}$ & $33.0 \mathrm{~cm}$ \\
\hline $\begin{array}{l}\text { Detrended acceleration (cm yrs) } \\
\text { trough-to-peak }\end{array}$ & $\begin{array}{l}6.4 \mathrm{~cm} \text { in } \\
100 \mathrm{yrs}\end{array}$ & $\begin{array}{l}10.0 \mathrm{~cm} \text { in } \\
100 \mathrm{yrs}\end{array}$ & $\begin{array}{l}13.4 \mathrm{~cm} \text { in } \\
200 \mathrm{yrs}\end{array}$ & $\begin{array}{l}17.0 \mathrm{~cm} \mathrm{in} \\
250 \mathrm{yrs}\end{array}$ & $\begin{array}{l}20.6 \mathrm{~cm} \mathrm{in} \\
300 \mathrm{yrs}\end{array}$ \\
\hline
\end{tabular}

850

851 Summary of nonlinear sinusoidal simulation (SIM) attributes tailored to the Pattagansett PXY cores. 852 Linear glacial isostatic adjustment (GIA) applied in all instances is equivalent to $0.11 \mathrm{~cm} / \mathrm{yr}$ (i.e. SIM 853 1). 
Table A.2 Summary goodness-of-fit for each non-linear simulation and modelling approach. Figures indicate the percentage of predicted values outside the $95 \%$ confidence interval for age and depth (not available for Bpeat). Values greater than $5 \%$ indicate the extent to which confidence intervals were too narrow (over-estimate of precision). Further details of model misfits are represented graphically in Figures A2 - A14.

860

\begin{tabular}{|c|c|c|c|c|c|}
\hline Age Misfit & SIM 2 & SIM 3 & SIM 4 & SIM 5 & SIM 6 \\
\hline Oxcal & $17.7 \%$ & $2.5 \%$ & $0.0 \%$ & $0.0 \%$ & $1.5 \%$ \\
\hline Bacon & $17.7 \%$ & $18.2 \%$ & $26.8 \%$ & $30.3 \%$ & $18.2 \%$ \\
\hline Bchron & $0.0 \%$ & $3.0 \%$ & $8.6 \%$ & $1.5 \%$ & $1.5 \%$ \\
\hline Clam & $9.6 \%$ & $12.2 \%$ & $9.6 \%$ & $16.8 \%$ & $12.7 \%$ \\
\hline Depth Misfit & SIM 2 & SIM 3 & SIM & SIM 5 & SIM 6 \\
\hline Oxcal & $19.1 \%$ & $5.0 \%$ & & $0.0 \%$ & $4.4 \%$ \\
\hline Bacon & $17.3 \%$ & $23.2 \%$ & $29.8 \%$ & $30.8 \%$ & $30.1 \%$ \\
\hline Bchron & $0.0 \%$ & $5.4^{\circ}$ & $9.2 \%$ & $0.0 \%$ & $2.5 \%$ \\
\hline Clam & $10.5 \%$ & $19.0 \%$ & $15.2 \%$ & $20.7 \%$ & $22.3 \%$ \\
\hline
\end{tabular}


863 Wright et al. - Reconstructing the accumulation history of a saltmarsh sediment core: Which 864 age-depth model is best?

865 Appendix B: Details of age data for Pattagansett River salt-marsh core

866 Table B.1 Accelerator mass spectrometry ${ }^{14} \mathrm{C}$ results

\begin{tabular}{|c|c|c|c|c|}
\hline $\begin{array}{l}\text { Lab no. } \\
\text { (UtC-) }\end{array}$ & $\begin{array}{c}\text { Depth } \\
(\mathrm{cm})\end{array}$ & $\begin{array}{l}\text { PMS } \\
(\mathrm{cm}) \\
\end{array}$ & $\begin{array}{r}\delta^{13} \mathrm{C} \\
\text { (p.mil) } \\
\end{array}$ & $\begin{array}{c}{ }^{14} \mathrm{C} \text { age } \\
\pm 1 \sigma \\
\end{array}$ \\
\hline 12834 & $29-30$ & $26 \pm 3$ & -13.4 & $145 \pm 29$ \\
\hline 12835 & $35-36$ & $32 \pm 3$ & -13.0 & $160 \pm 28$ \\
\hline 12836 & $41-42$ & $38 \pm 3$ & -12.9 & $157 \pm 29$ \\
\hline 12837 & $47-48$ & $44 \pm 3$ & -12.9 & $104 \pm 29$ \\
\hline 12838 & 53-54 & $50 \pm 3$ & -13.0 & $173 \pm 28$ \\
\hline 12839 & $59-60$ & $56 \pm 3$ & -13.0 & $334 \pm 30$ \\
\hline 12840 & $65-66$ & $62 \pm 3$ & -13.4 & $222 \pm 35$ \\
\hline 12841 & $71-72$ & $68 \pm 3$ & -13.9 & $364 \pm 37$ \\
\hline 12842 & $77-78$ & $74 \pm 3$ & -13.5 & $468 \pm 34$ \\
\hline 12843 & 83-84 & $80 \pm 3$ & -13.4 & $605 \pm 35$ \\
\hline 12844 & $89-90$ & $86 \pm 3$ & -13.4 & $571 \pm 36$ \\
\hline 12845 & $95-96$ & $92 \pm 3$ & -13.5 & $650 \pm 35$ \\
\hline 12846 & $101-102$ & $98 \pm 3$ & -13.6 & $760 \pm 35$ \\
\hline 12847 & $107-108$ & $104 \pm 3$ & -13.8 & $873 \pm 39$ \\
\hline 12848 & $113-114$ & $110 \pm 3$ & -13.8 & $1018 \pm 36$ \\
\hline 12849 & $119-120$ & $116 \pm 3$ & -14.3 & $991 \pm 43$ \\
\hline 12850 & $125-126$ & $122 \pm 3$ & -13.8 & $1043 \pm 38$ \\
\hline 12851 & $131-132$ & $128 \pm 3$ & -13.5 & $1186 \pm 35$ \\
\hline 12852 & $137-138$ & $134 \pm 3$ & -13.9 & $1113 \pm 37$ \\
\hline 12853 & $143-144$ & $140 \pm 3$ & -14.3 & $1188 \pm 35$ \\
\hline 12854 & $149-150$ & $146 \pm 3$ & -14.0 & $1169 \pm 37$ \\
\hline 12855 & $155-156$ & $152 \pm 3$ & -13.8 & $1213 \pm 38$ \\
\hline 12856 & $161-162$ & $158 \pm 3$ & -14.0 & $1309 \pm 38$ \\
\hline 12857 & $167-168$ & $164 \pm 3$ & -13.9 & $1471 \pm 36$ \\
\hline 12858 & $173-174$ & $170 \pm 3$ & -14.3 & $1544 \pm 37$ \\
\hline 12859 & $179-180$ & $176 \pm 3$ & -14.7 & $1532 \pm 35$ \\
\hline
\end{tabular}

867 All dated material consists of Spartina patens rhizomes. (Depth) sample depth in core; (PMS)

868 estimated depth of palaeo-marsh surface; $\left(\delta^{13} \mathrm{C}\right)$ abundance of ${ }^{13} \mathrm{C}$ relative to ${ }^{12} \mathrm{C}$ with respect to PDB 869 reference; $\left({ }^{14} \mathrm{C}\right.$ age $\left.\pm 1 \sigma\right){ }^{14} \mathrm{C}$ age in years before present $(\mathrm{BP})$ with associated $1 \sigma$ error and 870 normalised to $\delta^{13} \mathrm{C}=-25 \%$. Possible outlier based on linear wiggle-match shown in bold. 
872 Table B.2 Gamma spectrometry results

\begin{tabular}{|c|c|c|c|c|c|c|c|c|c|c|}
\hline $\begin{array}{l}\text { Depth } \\
(\mathrm{cm})\end{array}$ & $\begin{array}{l}\mathrm{DM} \\
(\mathrm{g}) \\
\end{array}$ & $\begin{array}{c}\text { CDD } \\
\left(\mathrm{g} / \mathrm{cm}^{3}\right) \\
\end{array}$ & $\begin{array}{l}\mathrm{xs}^{210} \mathrm{~Pb} \\
(\mathrm{~Bq} / \mathrm{kg})\end{array}$ & $\begin{array}{c} \pm \\
(\%) \\
\end{array}$ & $\begin{array}{r}{ }^{137} \mathrm{Cs} \\
(\mathrm{Bq} / \mathrm{kg}) \\
\end{array}$ & $\begin{array}{c} \pm \\
(\%) \\
\end{array}$ & $\begin{array}{l}{ }^{241} \mathrm{Am} \\
(\mathrm{Bg} / \mathrm{kg})\end{array}$ & $\begin{array}{c} \pm \\
(\%) \\
\end{array}$ & $\begin{array}{c}\text { pwCRS } \\
(\mathrm{yrs}) \\
\end{array}$ & $\begin{array}{c} \pm \\
(\mathrm{yrs}) \\
\end{array}$ \\
\hline 1 & 12.085 & 0.19 & 321.23 & 6.88 & 5.86 & 10.42 & - & - & 2.47 & 0.17 \\
\hline 2 & 13.243 & 0.40 & 201.54 & 8.88 & 2.34 & 11.31 & - & - & 6.04 & 0.54 \\
\hline 3 & 10.508 & 0.56 & 119.68 & 10.75 & 3.02 & 13.32 & - & - & 9.37 & 1.02 \\
\hline 4 & 9.997 & 0.72 & 83.86 & 12.86 & 4.32 & 12.21 & 0.07 & 54.27 & 12.69 & 1.65 \\
\hline 5 & 9.119 & 0.86 & 70.86 & 10.09 & 7.65 & 8.37 & 0.42 & 29.64 & 16.44 & 1.67 \\
\hline 6 & 11.639 & 1.04 & 56.50 & 10.86 & 5.43 & 10.56 & 0.09 & 44.42 & 20.54 & 2.25 \\
\hline 7 & 12.085 & 1.23 & 55.09 & 10.68 & 4.32 & 10.64 & - & - & 26.01 & 2.81 \\
\hline 8 & 8.697 & 1.37 & 42.58 & 8.88 & 3.42 & 13.42 & - & - & 31.59 & 2.84 \\
\hline 9 & 12.085 & 1.55 & 31.25 & 12.20 & ${ }^{*} 34.42$ & 7.53 & - & - & 37.13 & 4.59 \\
\hline 10 & 12.764 & 1.75 & 27.81 & 13.05 & 12.31 & 6.53 & - & - & 43.86 & 5.81 \\
\hline 11 & 13.352 & 1.96 & 17.60 & 13.07 & ${ }^{*} 26.52$ & 5.78 & 0.66 & 21.31 & 49.65 & 6.59 \\
\hline 12 & 11.315 & 2.14 & 2.60 & 9.76 & 11.21 & 9.75 & - & - & 50.69 & 5.03 \\
\hline 13 & 12.085 & 2.33 & 2.38 & 9.52 & 8.65 & 8.49 & - & - & 51.76 & 5.01 \\
\hline 14 & 35.102 & 2.88 & 3.37 & 8.56 & 7.54 & 10.52 & - & - & 53.72 & $\begin{array}{r}4.68 \\
\end{array}$ \\
\hline 15 & 12.085 & 3.07 & 5.77 & 9.35 & 5.43 & 11.15 & - & - & 61.64 & 5.49 \\
\hline 16 & 10.346 & 3.23 & 6.42 & 11.42 & 4.67 & 12.31 & - & - & 64.40 & 7.34 \\
\hline 17 & 12.259 & 3.42 & 16.03 & 15.76 & 2.65 & 10.53 & - & - & 86.68 & 13.62 \\
\hline 18 & 12.413 & 3.61 & 5.55 & 10.66 & 2.43 & 12.35 & - & - & 101.33 & 10.76 \\
\hline 19 & 12.085 & 3.80 & 2.14 & 13.33 & 1.31 & 12.61 & - & - & 109.93 & 14.59 \\
\hline 20 & 21.075 & 4.13 & 1.44 & 10.88 & 1.86 & 13.67 & - & - & 118.07 & 12.77 \\
\hline 21 & 10.56 & 4.30 & 0.14 & 14.42 & 1.62 & 14.57 & - & - & 119.01 & 17.06 \\
\hline 22 & 10.034 & 4.45 & 0.08 & 13.24 & 1.88 & 14.67 & - & - & 118.85 & 15.74 \\
\hline 23 & 12.273 & 4.64 & 0.08 & 18.34 & 1.25 & 15.15 & - & - & 119.45 & 21.91 \\
\hline 24 & 9.233 & 4.79 & 0.45 & 17.87 & 1.10 & 13.63 & - & - & 123.16 & 22.01 \\
\hline 25 & 8.601 & 4.92 & 0.13 & 16.21 & 1.07 & 10.68 & - & - & 134.32 & 20.15 \\
\hline 26 & 9.197 & 5.07 & 0.01 & 15.41 & 0.97 & 11.78 & - & - & 134.37 & 19.16 \\
\hline 27 & 10.017 & 5.22 & 0.01 & 16.28 & 1.44 & 12.47 & - & - & 134.52 & 20.27 \\
\hline 28 & 13.763 & 5.44 & 0.02 & 15.17 & 1.11 & 10.68 & - & - & 144.78 & 18.93 \\
\hline 29 & 12.352 & 5.63 & 0.22 & 15.06 & 2.17 & 12.31 & - & - & 147.24 & 19.16 \\
\hline 30 & 11.035 & 5.80 & 0.08 & 15.31 & - & - & - & - & 148.19 & 19.63 \\
\hline 31 & 31.165 & 6.29 & 0.05 & 17.00 & - & - & - & - & 148.81 & 21.90 \\
\hline 32 & 31.036 & 6.78 & 0.04 & 18.16 & - & - & - & - & 149.41 & 23.51 \\
\hline 33 & 31.165 & 7.26 & 0.19 & 17.85 & - & - & - & - & 152.67 & 23.68 \\
\hline 34 & 30.807 & 7.74 & 0.03 & 15.31 & - & - & - & - & 163.21 & 20.40 \\
\hline 35 & 13.724 & 7.96 & 0.00 & 19.05 & - & - & - & - & 163.30 & 25.40 \\
\hline 36 & 20.628 & 8.28 & 0.06 & 17.93 & - & - & - & - & 174.59 & 24.13 \\
\hline 37 & 13.492 & 8.49 & 0.06 & 16.94 & - & - & - & - & 185.90 & 23.02 \\
\hline
\end{tabular}




\begin{tabular}{|c|c|c|c|c|c|c|c|c|c|c|}
\hline 38 & 20.352 & 8.81 & 0.07 & 15.91 & - & - & - & - & 187.67 & 21.90 \\
\hline 39 & 18.845 & 9.10 & 0.00 & 18.03 & - & - & - & - & 187.68 & 24.82 \\
\hline 40 & 14.387 & 9.33 & 0.06 & 22.96 & - & - & - & - & 189.28 & 31.98 \\
\hline 41 & 14.498 & 9.55 & 0.27 & 24.24 & - & - & - & - & 198.14 & 35.91 \\
\hline 42 & 8.633 & 9.69 & 0.10 & 22.04 & - & - & - & - & 202.25 & 33.56 \\
\hline 43 & 8.369 & 9.82 & 0.13 & 23.79 & - & - & - & - & 208.54 & 67.73 \\
\hline 44 & 7.618 & 9.94 & 0.12 & 21.99 & - & - & - & - & 215.66 & 76.44 \\
\hline 45 & 6.156 & 10.04 & 0.02 & 20.10 & - & - & - & - & 216.85 & 83.54 \\
\hline 46 & 8.092 & 10.16 & 0.03 & 19.89 & - & - & - & - & 219.13 & 93.65 \\
\hline 47 & 7.945 & 10.29 & 0.02 & 23.43 & - & - & - & - & 220.65 & 99.98 \\
\hline 48 & 7.881 & 10.41 & 0.38 & 21.40 & - & - & - & - & - & - \\
\hline
\end{tabular}

873 Results consist of (DM) sample dry mass, (CDD) cumulative dry density, (xs $\left.{ }^{210} \mathrm{~Pb}\right)$ excess ${ }^{210} \mathrm{~Pb}$

874 provided by total ${ }^{210} \mathrm{~Pb}$ minus ${ }^{226} \mathrm{Ra}$, (pwCRS) 'piecewise' constant rate of supply age-depth model

875 using a core top age of AD2002 and AD1963 ${ }^{137} \mathrm{Cs}$ spike at $9 \mathrm{~cm}$ core depth. 
1 Wright et al. - Reconstructing the accumulation history of a saltmarsh sediment core: Which age-

2 depth model is best?

3 Highlights

4 - The performance of five age-depth modelling programs is evaluated using synthetic and real data

5 - Reconstruction accuracy and precision varies but no single model is best

6 - Simulation reveals the smallest resolvable accumulation change in a core

7

- No models produce spurious oscillations that will distort sea-level reconstructions

8

- Increased accumulation rate in our core since AD1800 is not an artefact of data type 